\title{
Exploring the ability of current climate information to facilitate local climate services for the water sector
}

\author{
Aristeidis G. Koutroulis ${ }^{1}$, Manolis G. Grillakis ${ }^{1}$, loannis K. Tsanis ${ }^{1,2^{*}}$ and Daniela Jacob ${ }^{3}$
}

\begin{abstract}
Local climate services become increasingly necessary in making adaptation to our changing climate more understandable and manageable. The ability of current climate information to develop and support local climate services for water resources management in close collaboration with local users of the water sector from the island of Crete is being explored. Climate modeling output ranging from event scale to decadal and centennial experiments, at hourly to monthly temporal scales and at high resolution (2 Km) to GCM spatial scales $(100-250 \mathrm{~km})$, are used to assess climate change impacts on water resources availability and extremes. A robust signal of temperature increase and precipitation decrease is projected for all future periods, in parallel to an increase in magnitude of extreme precipitation. Several messages could be extracted from the provider - user interaction such as the communication of basic concepts and uncertainties, user skepticism and feedback. The frequent personal contact, the communication in layman's terms of the limitations of the climate impact modeling and the corresponding uncertainties, is the key to successful provisions of suitable information.
\end{abstract}

Keywords: Climate change, Climate impacts, Climate services, Water resources, Hydrological modeling, Extremes, Mediterranean, Crete Island

\section{Background and user needs}

Climate is changing and so is the perception about the impact of human intrusiveness. The increasing demands of the growing population will put further pressures on the climate and the environment. In order to meet the challenges of climate change the development of both climate modelling and science for climate services is required (Hewitt et al. 2012; Hewitt et al. 2013). The provisions of suitable information on climate change and variability for supporting decision making at all levels of society can be described as climate service (Vaughan \& Dessai 2014). The current situation in the field of climate services can be characterized by increasing needs and by the need to adjust practices and procedures adjustment in order to offer modern products and

\footnotetext{
*Correspondence: tsanis@hydromech.gr; tsanis@mcmaster.ca

${ }^{1}$ Department of Environmental Engineering, Technical University of Crete,

Chania, Greece

${ }^{2}$ Department of Civil Engineering, McMaster University, Hamilton, ON,

Canada

Full list of author information is available at the end of the article
}

services, meeting the needs of a changing society (Bokoye et al. 2014; Guido et al. 2013).

Regarding the water sector, climate change is likely to increase the regional and global water stress considerably. A $15 \%$ of the global population will probably face a severe decrease of water availability from $2{ }^{\circ} \mathrm{C}$ warmer climate, based on an ensemble of global hydrological projection (Schewe et al. 2014). In the majority of climate impact studies Mediterranean is projected as one of the most vulnerable areas to climatic and anthropogenic changes (Navarra \& Tubiana 2013). Model projections reveal a continual and gradual warming trend while exceptional hot summers during the control period may become "typical" by the end of the $21^{\text {st }}$ century (Kostopoulou et al. 2013). Decreasing annual rainfall trends and an increasing number of extreme precipitation events are present in most projections from both global and regional climate models and are consistent across emission scenarios, concentration pathways and future time periods (Ludwig et al. 2011). Currently, the southern and eastern rims are experiencing high to severe water stress induced by human and 
climatic drivers. Future scenarios for water resources in the Mediterranean region suggest a progressive decline in the average stream flow (García-Ruiz et al. 2011; Murray et al. 2012). By the 2050s, this stress could increase over the whole Mediterranean basin, notably because of a 30-50\% decline in freshwater resources as a result of climate change (Milano et al. 2013). Models foresee a robust largescale change of the surface water balance and the partitioning of precipitation between evapotranspiration, runoff, and groundwater flow (Schewe et al. 2014; García-Ruiz et al. 2011; Arnell et al. 2011; Tsanis et al. 2011). At the same time increasing climate change induced temperatures will most likely increase the need for irrigation in agriculture. Irrigation potential will be reduced by decreasing runoff and aquifer recharge. Overexploitation and water conflicts will also probably increase between different water consuming sectors (Santos et al. 2013).

The current financial stress of the southern European countries and the continuously reduced national investment programmes call for low cost, short and long term water management strategies in order to tackle the climate induced changes in water resources (Koutroulis et al. 2013). All the above indicates the necessity to improve and update local water management planning and adaptation strategies in order to attain future water security, and thus specialized climate services supporting these actions is of crucial importance. Climate services have to be tailored to the local context. There is an increasing call for local measures to adapt to climate change, based on foresight analyses in collaboration with actors. However, such analyses involve many challenges, particularly because the actors concerned may not consider climate change to be an urgent concern (Faysse et al. 2012).

The objective of the study is to present in detail analysis and post-processing of climate output for the extraction of climate information in its most useful and manageable form, meeting the needs of a local user of the water sector, the Directorate of Water of the decentralized administration of the island of Crete. The Directorate of Water is responsible for the water distribution and availability. Planning involves domestic and irrigation use infrastructure and policy development. Currently the Regional Authority owns a large number of hydro-meteorological stations over the island that allow for an adequate modelling of the current conditions. The availability of future climate data, during the $21^{\text {st }}$ century, is crucial for the development of water management scenarios and risk assessment of future water availability. Moreover the Directorate of Water as the general water managing authority in the Prefecture of Crete is also responsible for the implementation of the European Water Framework Directive (WFD) for the corresponding hydrological compartment (GR13). The implementation of the WFD is based on
6 years term management plans. The first draft management plan was developed during the course of the ECLISE project and information regarding short term experiments such as decadal projections was considered as very useful and appropriate for this application. At the same time, an assessment of the severity and frequency of future precipitation extremes is also important in order to update the policies infrastructure design.

Interaction with the local management authority lead to the identification of the user needs. Figure 1 illustrates the identified user needs, associated source of information and corresponding temporal scales. These needs are related to climate modelling outputs ranging from event scale to decadal and centennial experiments, at temporal scales ranging from hourly to monthly, and at spatial scales from very high resolution regional climate models (2 km) to typical GCMs (100-250 km).

Centennial scale experiments were used in order to assess climate change impacts on water resources availability combined with estimates of the potential future water demand of the island of Crete. A Grand Ensemble of specialized hydrological information was structured from 45 realizations by seven GCMs within the frame of CMIP5 (under RCPs 2.6-14 realizations, 4.5-16 realizations and 8.5-15 realizations), from three GCMs (under SRES A2 and B1, in the frame of CMIP3 - one realization) and from 10 RCMs downscaling eight CMIP3 driving GCMs (ENSEMBLES FP6, under SRES A1B - one realization). Each member of this ensemble was bias adjusted against local observations. The range of projected information among the different emission scenarios, different climate model setups and scale represent a wide range of the uncertainty assessed in the projected hydroclimatology of the region. The continuous rainfall-runoff model SAC-SMA was used to estimate the hydrologic impact during the $21^{\text {st }}$ century for the study area. Water availability for the whole island was then estimated for a range of different scenarios of projected hydro-climatological regime, demand and supply potential. Regarding the shorter term water management planning according to the European Water Framework Directive (WFD), the ability of decadal GCM prediction experiments to reproduce basic hydro-meteorological variables like precipitation and temperature, was also examined.

In terms of potential future changes in extreme events related to precipitation the recurrence intervals of specific magnitude was studied using the Annual Exceedance Probability (AEP) approach. Additionally, three special cases were framed, for demonstrating high resolution climate modeling applications of extreme flood events over the case study area and the evolution of the corresponding events at $\mathrm{a}+2{ }^{\circ} \mathrm{C}$ warmer climate. This application had a dual purpose, firstly to convince the user for the capabilities of climate modeling against scaling uncertainty and 


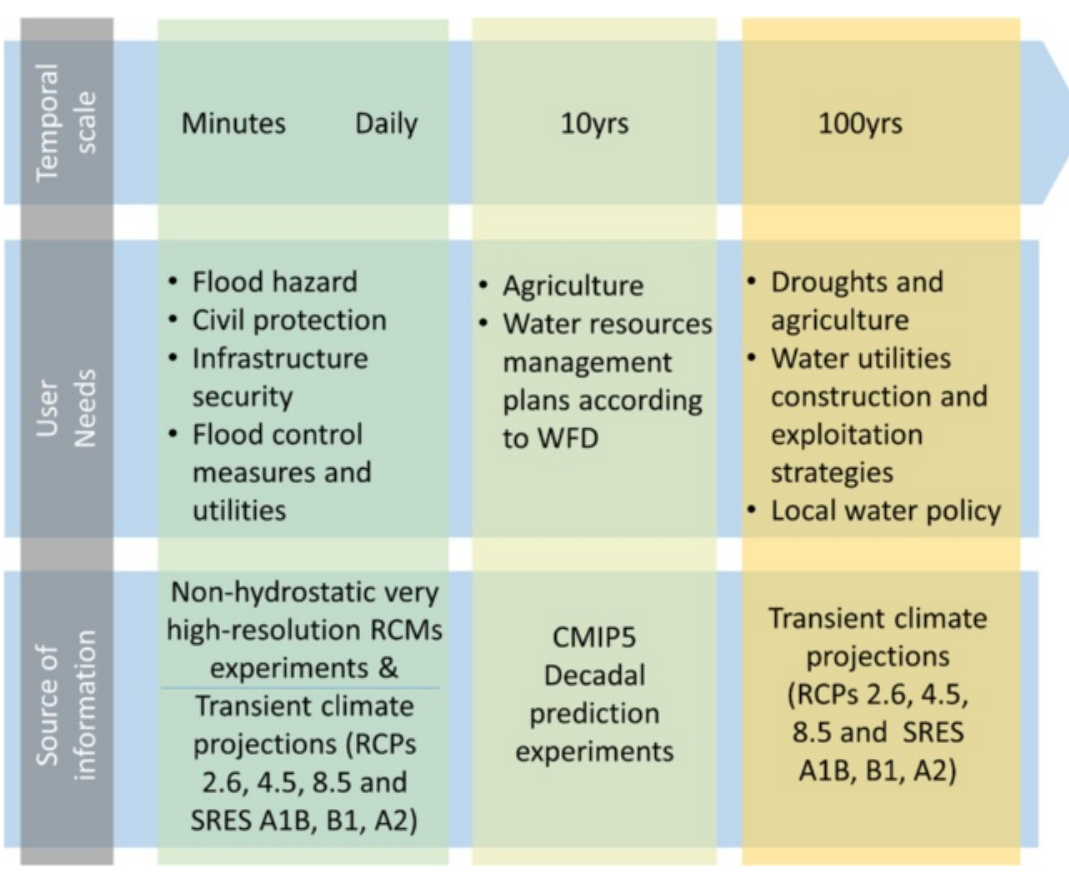

Fig. 1 Illustration of identified user needs, associated source of information and corresponding temporal scales

secondly to test the high resolution modeling capability of realistic representation of such events.

The final product of the communication with the end user and the research instigated by this interaction, were technical reports, future climate statistics and time series on meteorologic variables and rainfall-runoff simulations supporting water availability decision-making, as well as statistics of projected precipitation extremes in terms of recurrence intervals delivered to the Regional Authority for Water Resources Management of Crete.

\section{Area of study and climate information Study area}

The island of Crete occupies the southern part of the country of Greece (Fig. 2) and with an area of about $8300 \mathrm{~km}^{2}$, Crete covers more than $6 \%$ of the area of
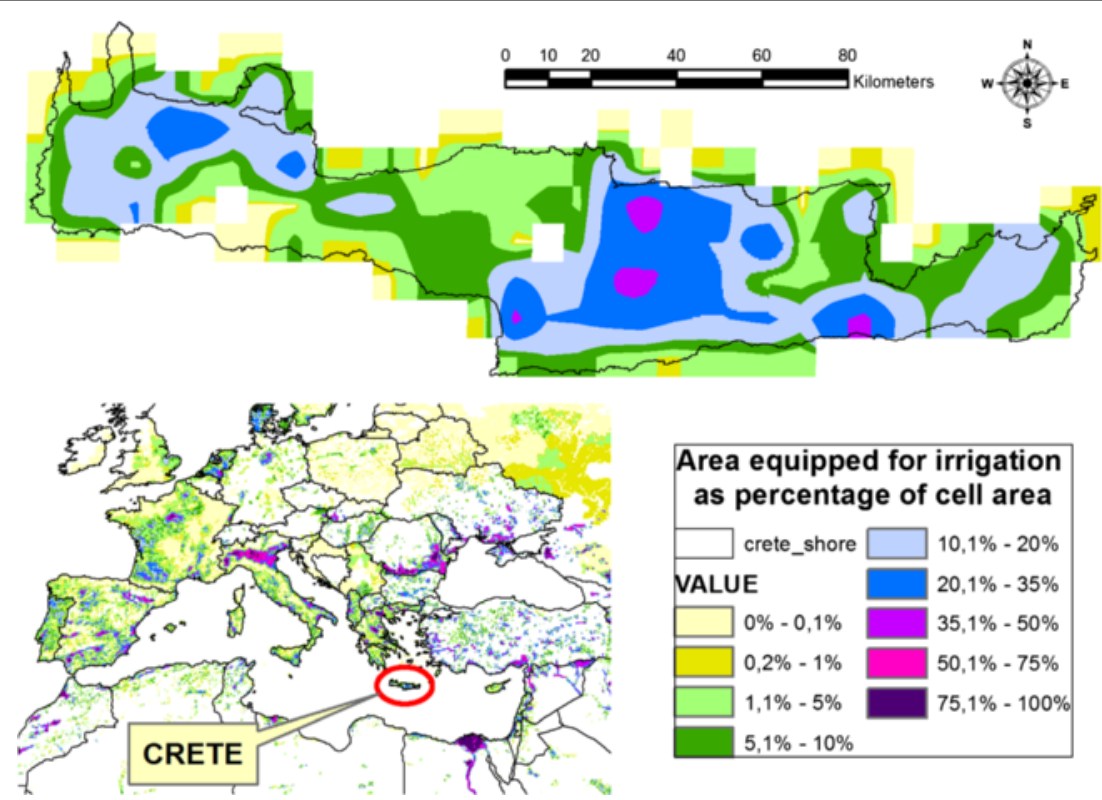

Fig. 2 Location of the island of Crete, Greece and areas equipped with irrigation systems (source: FAO-Aquastat, 2007) 
Greece and is the $5^{\text {th }}$ largest of the Mediterranean islands. The mean elevation is $482 \mathrm{~m}$ and the complex topography carved by ephemeral streams shaping small steep catchments. The climate is dry sub-humid Mediterranean characterized by warm dry summers and cold humid winters. More than $40 \%$ of the annual precipitation occurs in the winter months. Average precipitation ranges from $440 \mathrm{~mm} /$ year on the eastern part of the island to more than $2000 \mathrm{~mm} /$ year on the highland western parts, where orographic effects tend to increase both frequency and intensity of winter precipitation (Koutroulis et al. 2010; Koutroulis \& Tsanis 2010; Koutroulis et al. 2012).

Total water use in the region in 2000 amounted to 420 million $\mathrm{m}^{3}$, approximately $6.3 \%$ of the precipitation of a normal year (Papagrigoriou et al. 2001). $16 \%$ is used for domestic, tourist, and industrial uses, $3 \%$ for livestock and a vast $81 \%$ for irrigated agriculture on less than $30 \%$ of the total cultivated land (Fig. 2), using mainly ground water in drip irrigation methods.

The intense development of Crete during the last decades has exerted strong pressure on many sectors in the region. Summer irrigation and summer (beach) tourism create peak demands with an annual volume of water abstracted exceeding $50 \%$ of the average annual runoff and $35 \%$ of the groundwater potential. Despite the recent financial crisis, water use in Crete is continuously increasing. The Crete region has also suffered from numerous severe flood and flash flood events in the past decades. They have been the result of a combination of factors ranging from extreme climatic conditions and poor flood mitigation measures. Upgrading facilities for extreme events readiness is a major effort.

\section{Local datasets}

The observational dataset for the assessment of the water resources availability is structured from records in the period 1973-2005. It consists of daily precipitation at 53 precipitation stations, runoff at 22 stations, 15 temperature stations and 18 pan Evaporation stations. Regarding the demonstration cases of non-hydrostatic high-resolution RCMs runs the following observations were used to support their evaluation:

- November 17, 2006 - the Almirida basin flash flood event.

50 stations of daily accumulated precipitation and 3 stations of 10 min time step recording. A well-documented flash flood event with available rainfall runoff modeling data

- January 13, 1994 - the Giofiros basin flash flood event 50 stations of daily accumulated precipitation. A well-documented flash flood event with available rainfall runoff modeling data

- November 22, 2008 - the Ierapetra flash flood event
44 stations of daily accumulated precipitation and 13 stations 10 min time step recording.

A detailed description of the events is included in (Sobolowski et al. 2014).

\section{Long term transient experiments The ensembles dataset}

Ten (10) different RCMs runs of the Ensembles FP6 project (Tsanis et al. 2011; Van der Linden 2009) focusing on the Island of Crete over the European continent were used, at a horizontal resolution of about $25 \mathrm{~km}$. The RCMs' lateral boundary conditions were provided by 8 GCMs (CMIP3) for the period 1951-2100 (Table 1).

All simulations were forced using observed GHG greenhouse gas and aerosol concentrations until 2000 and SRES A1B concentrations scenario until 2100. Specific metrics based on distribution matching and seasonality representation criteria (Hesselbjerg Christensen et al. 2010) were used for the synthesis of an optimal ensembles. Details on regional climate models skill-weights is described in detail by Koutroulis et al. (2013) as well as the procedure followed to adjust precipitation and temperature for biases.

\section{The WATCH dataset}

Six additional datasets available for the period 20012100 based on 3 different cMIP3 GCMs (Echam5, IPSL, and CNRM) and two emission scenarios (A2 and B1), at a spatial resolution of $0.5^{\circ}$, were used for analysis. These datasets were developed in the context of WATCH FP6 European funded project (Weedon et al. 2010; Haddeland et al. 2011) and are publicly available from the Centre of Ecology and Hydrology (CEH) through [https:// eip.ceh.ac.uk/]. Further information about data processing are detailed by Koutroulis et al. (Koutroulis et al. 2013).

Table 1 List of ensembles FP6 Regional Climate models (RCMs)

\begin{tabular}{lllll}
\hline No & Institute & RCM & Driving GCM & References \\
\hline 1 & ETH & CLM & HadCM & (Jaeger et al. 2008) \\
2 & ICTP & RegCM & ECHAM5-r3 & (Giorgi \& Mearns 1999) \\
3 & KNMI & RACMO2 & ECHAM5-r3 & (Van Meijgaard et al. 2008) \\
4 & METOHC & HadRM3Q0 & HadCM3Q0 & (Collins et al. 2010) \\
5 & METOHC & HadRM3Q3 & HadCM3Q3 & (Collins et al. 2010) \\
6 & METOHC & HadRM3Q16 & HadCM3Q16 & (Collins et al. 2010) \\
7 & C4I & RCA3 & HadCM3Q16 & (Kjellstrom et al. 2005) \\
8 & MPI & REMO & ECHAM5-r3 & (Jacob 2001) \\
9 & SMHI & RCA & BCM & (Kjellstrom et al. 2005) \\
10 & DMI & HIRHAM & ARPEGE & (Christensen et al. 2006) \\
\hline
\end{tabular}




\section{The COMBINE dataset}

The main aim of COMBINE FP7 European funded project was to implement new processes in ESMs in order to advance climate prediction and projection capabilities. Outputs from four Earth System Models (CMCC-CESM, MPI-ESM-MR, HadGEM2-ES and NorESM-M) and three AOGCMs (EC-EARTH, IPSL-CM5-LR and CNRM-CM5) were analysed within COMBINE framework (Table 2), under three Representative Concentration Pathways (RCPs 2.6, 4.5 and 8.5) for a total of 45 realizations, and used in the ELCISE project as climate information of the new CMIP5 modelling experiment. These models covers an adequate range of climate sensitivities in the CMIP5 experiment (Sherwood et al. 2014; Andrews et al. 2012). The spatial resolution of the models used ranges from 1.125 to $3.75^{\circ}$.

\section{Decadal prediction experiments}

Decadal prediction experiments within the CMIP5 protocol were also analyzed in order to examine the ability of realistic reproduction of decadal trends and number of wet and dry years useful for short term resources planning. A large number of different initializations and realizations (totally 439) from five contributing models (Table 3) were analyzed. More specifically, the decadal predictions experiments have been performed following the WCRP/CMIP5 protocol (Taylor et al. 2012) with simulations starting from 1960 and every five years up to 2005. Regarding initialization strategy, CMCC-CM was initialized using full-values from three different ocean analyses using the CMCC-INGV ocean syntheses (Bellucci et al. 2007; Storto et al. 2011) and different assimilation methods. For CNRM-CM5 initial states were produced from coupled experiments in which a surface flux correction was applied to constrain SST. EC-Earth used a full initialization approach using the ECMWF/ NEMOVAR adding small perturbations to the atmospheric initial state. The initial conditions for the 10 HadCM3 (Smith et al. 2007) hindcasts were produced by randomly perturbing the SSTs slightly with white noise. MPI-ESM-LR, which is the only Earth System Model (the previously described models are AOGCMs), hindcasts were based on an assimilation run performed by nudging temperature and salinity anomalies from the ORAS3 reanalysis (Kröger et al. 2012).

\section{Non-hydrostatic high-resolution RCMs experiments}

High-resolution non-hydrostatic regional climate modelling experiments (NHRM) were conducted for the selected cases over the island of Crete (Sobolowski et al. (2014). Three models (i) HCLIM by SMHI (Lindstedt et al. 2013), (ii) HARMONIE by KNMI (Van der Plas et al. 2012) and (iii) WRF by UNI (Hong \& Lim 2006), were set up and run for a model domain covering the island of Crete at a past climate and a warmer climate $\left(+2{ }^{\circ} \mathrm{C}\right)$ mode. All models were set up at a convective permitting resolutions of about $2 \mathrm{~km}$ for a domain covering Crete island, extending from $34.0 \mathrm{~N}, 22.4 \mathrm{~W}$ (lower left corner) to $37.2 \mathrm{~N}, 27.7 \mathrm{~W}$ (upper right). Simulations were performed for the three selected extreme events, starting one or two days ahead, leading to three time slices of about four to five days. Model were run for two sets of experiments, the present day (real cases) and the warmer climate $\left(+2{ }^{\circ} \mathrm{C}\right)$ situation. Present day simulations performed using lateral boundaries from downscaled ERAInterim reanalysis (Dee et al. 2011) with frequent reinitializations (every $6 \mathrm{~h}$ ). REMO regional climate model was used to dynamically downscale the ERA-Interim at approximately $12 \mathrm{~km}$ resolution. Similar simulations, but with a perturbation of $+2{ }^{\circ} \mathrm{C}$ that was applied uniformly to the lateral and surface boundary conditions were conducted for the representation of warmer climate conditions.

\section{Methods}

\section{Case study framework}

An established assessment framework was used (Koutroulis et al. 2013) which was based on a previous study but also extended from communication and new interactions with the user during the project (Fig. 3). The climate models

Table 2 CMIP5 RCPs simulations

\begin{tabular}{llllll}
\hline & \multicolumn{2}{l}{ Realizations } & & Horiz. Resol. & References \\
\cline { 2 - 5 } Model & RCP2.6 & RCP4.5 & RCP8.5 & & (Davini et al. 2013) \\
\hline CMCC-CESM & 1 & 3 & 1 & $1.75^{\circ} \times 3.75^{\circ}$ & (Roeckner et al. 2006) \\
MPI-ESM-MR & 3 & 3 & 3 & $1.875^{\circ} \times 1.875^{\circ}$ & (Hazeleger et al. 2011) \\
EC-Earth & 4 & 4 & 4 & $1.125^{\circ} \times 1.125^{\circ}$ & (Collins et al. 2011) \\
HadGEM2-ES & 4 & 4 & $4.75^{\circ} \times 1.25^{\circ}$ & (Dufresne et al. 2013) \\
IPSL-CM5-LR & 1 & 1 & 1 & $1.4^{\circ} \times 1.4^{\circ}$ & (Voldoire et al. 2012) \\
CNRM-CM5 & 1 & 1 & 1 & $2.5^{\circ} \times 1.875^{\circ}$ & (Bentsen et al. 2013) \\
NorESM-M & 14 & 16 & 15 & &
\end{tabular}


Table 3 Decadal prediction datasets from CMIP5 archive

\begin{tabular}{llllllllllll}
\hline & \multicolumn{1}{l}{ Realizations } & \multicolumn{1}{l}{ Model } & 1970 & 1975 & 1980 & 1985 & 1990 & 1995 & 2000 & 2005 & 2010 \\
\hline CMCC-CM & 3 & 3 & 3 & 3 & 3 & 3 & & 3 & 0 & (Scoccimarro et al. 2011) \\
CNRM-CM5 & 10 & 10 & 10 & 10 & 10 & 10 & 10 & 10 & 0 & (Voldoire et al. 2012) \\
EC-Earth-KNMI & 11 & 11 & 11 & 11 & 11 & 11 & 11 & 11 & 0 & (Du et al. 2012) \\
HadCM3 & 20 & 20 & 20 & 20 & 20 & 20 & 20 & 20 & 0 & (Collins et al. 2001) \\
MPI-ESM-LR & 10 & 10 & 10 & 10 & 10 & 10 & 10 & 10 & 10 & (Raddatz et al. 2007) \\
Total & 54 & 54 & 54 & 54 & 54 & 54 & 51 & 54 & 10 & \\
\hline
\end{tabular}

output analysis was based on one 30-year and two 50-year discrete periods over Crete in the COMBINE, WATCH and ENSEMBLES domains as illustrated in Fig. 3. The control period (1970-2000) was used for weighting of ENSEMBLES RCMs, bias correction of COMBINE, WATCH and ENSEMBLES model results and interpretation for the two future (2000-2050 and 2050-2100) periods. The projected hydrologic regime was also distinguished in two time periods (2000-2050 and 2050-2100) for the three pathways (RCPs 2.6, 4.5 and 8.5) and three emission scenarios (B1, A2 and A1B) based on the hydrologic simulation of the COMBINE, WATCH and ENSEMBLES climate model input data through continuous rainfallrunoff modelling.

\section{Bias adjustment}

In order to optimally remove the systematic bias of the modeled precipitation, a new methodology that was developed in the frame of European funded projects, including ECLISE FP7, is applied to climate model outputs. The methodology belongs to the widely used family of quantile mapping correction methods. The method uses different instances of gamma function that are fitted on multiple discrete segments on the precipitation CDF, instead of the common quantile-quantile approach that uses one theoretical distribution to fit the entire
CDF. This gives the method the ability to better adjust raw climate model statistics towards the observations. The selection of the segment number is performed by an information criterion to poise between complexity and efficiency of the transfer function. The methodology was tested on CMIP3 global climate models resulting to a very good performance in reducing the systematic biases of the climate model data. Details of the methodology and the validation are presented in (Grillakis et al. 2013).

For decadal predictions we adopted a simple correction method that adjusts both mean and standard deviation by applying the average difference from the observations and a stretch factor obtained from the ratio of standard deviations of observations and model outputs (Haerter et al. 2011).

\section{Hydrologic modelling}

Hydrologic modelling was performed with the use of the continuous rainfall-runoff model SAC-SMA (Sacramento) model (Tsanis \& Apostolaki 2008). Precipitation and potential evapotranspiration are used as model inputs to generate an estimated flow which can be used to calibrate the model with a genetic algorithm optimization process (Wang 1997). The objective function of the optimization is the Nash-Sutcliffe model accuracy statistic. An optimization method based on genetic algorithms was used

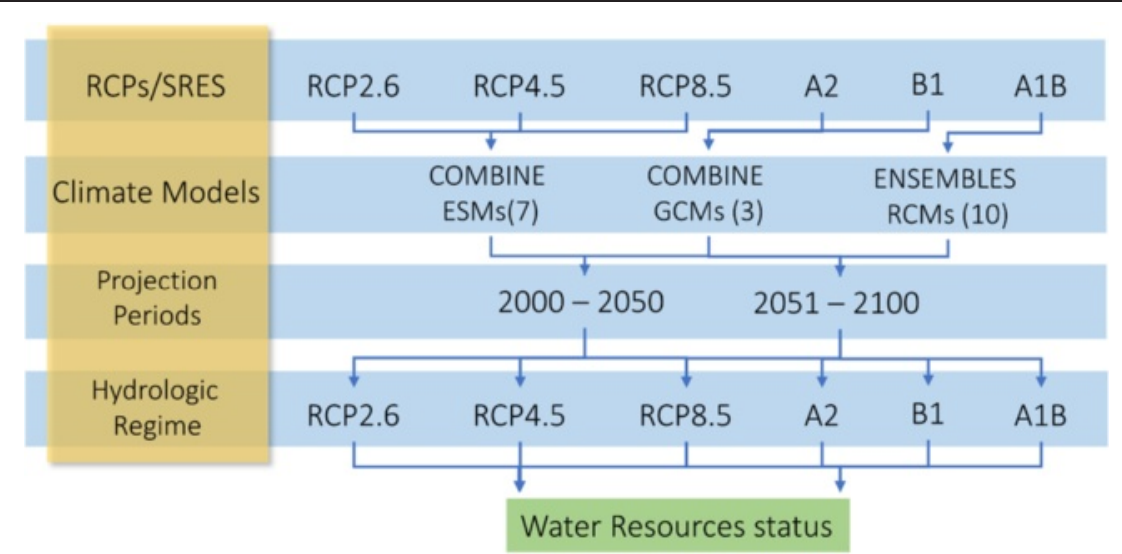

Fig. 3 Water resources assessment framework for Crete study site 
in 17 gauged basins using a monthly time step. In general, the calibration yielded satisfactory results with the NashSutcliffe criterion between 0.51 and 0.90. The averaging for all 110 basin parameters was implemented using a "naive" parameter to make estimations for the total area of the island of Crete (Tsanis et al. 2011).

\section{Annual exceedance probability}

Changes in the recurrence intervals of specific magnitude events are studied using the Annual Exceedance Probability (AEP) approach (Eash et al. 2013). Generalized Extreme Value (GEV) distributions are fitted on the annual maximum values of precipitation (the maximum of each year). Following the rule that a theoretical curve can be extended to as far as the double size of the fitted sample, it is safe to extrapolate the distributions to as far as $1 \%$ AEP (Grillakis et al. 2011; IACWD 1982; Swain 2004). The agreement of the estimated AEP between the observed and the bias corrected historical data is also an indicator of the quality of the bias correction and therefore for the respective results of the projection period data.

\section{Results}

\section{Projections of water availability}

The already insufficient water availability is projected to decrease and current water stress will further intensify. For all emission scenarios the signals of increasing temperature and decreasing precipitation and water availability are robust. Table 4 summarizes the projected hydrological changes for all pathways/scenarios and multi-model ensemble for the two reference periods according to the water resources assessment framework for Crete (Fig. 3). Detailed results for ENSEMBLES and WATCH FP6 modelling results are included in (Tsanis et al. 2011; Koutroulis et al. 2013) so the present study is focused more in the outputs of the new COMBINE (CMIP5) model outputs illustrated in Fig. 4 to see where these lie in the range of results from the previous modeling efforts. Projected precipitation, temperature and water availability based on RCPs 2.6, 4.5 and 8.5 are shown in this figure. It is also important to note that projections for RCPs 2.6, 4.5 and 8.5 and for the SRES A2 and B1 are based on CMIP5 and CMIP3 GCMs with an average resolution about $1.5^{\circ}$ compared to the $\mathrm{A} 1 \mathrm{~B}$ results that comes from higher resolution $(25 \mathrm{~km}) \mathrm{RCMs}$ runs.

A parallel increase of temperature with higher concentration of greenhouse gases is expected for the region of Crete resulting in a reduction of precipitation and therefore available water resources. The increasing temperature trend as projected by the multi-model ensemble ranges from $0.28{ }^{\circ} \mathrm{C} /$ decade according to $\mathrm{RCP} 2.6$, to $0.34{ }^{\circ} \mathrm{C} / \mathrm{dec}-$ ade for $\mathrm{RCP} 4.5$ and $0.59{ }^{\circ} \mathrm{C} /$ decade for $\mathrm{RCP} 8.5$. The corresponding precipitation trend range from a slight negative for RCP2.6 to a negative $0.9 \%$ /decade for RCP4.5 and $-2 \%$ for RCP8.5. The combined effect on water availability is an approximate decreasing trend of $2 \%$ /decade for RCPs 2.6 and 4.5 and $-3 \%$ /decade for RCP8.5. The similar decreasing water availability trends for RCPs 2.6 and 4.5 could be an indication that the main driver of the reduction is temperature increase leading to increased evaporation losses.

Temperature increase for the 2000-2050 reference period ranges between 1.4 and $1.9^{\circ} \mathrm{C}$ with an average multi-model range of roughly $\pm 0.5{ }^{\circ} \mathrm{C}$. Both the rising intensity of the temperature $\left(2.0-5.1{ }^{\circ} \mathrm{C}\right)$ and the range of the projections are increased for the next reference period $\left(-2.2\right.$ to $\left.+1.3^{\circ} \mathrm{C}\right)$ as can be seen from the results included in Table 4.

Multimodel GCM outputs presents a blended signal of a generally slight reduction of precipitation in the range of $-5 \%$ to $+6 \%$ compared to baseline. ENSEMBLES results based on RCMs outputs indicate a more severe precipitation reduction. This signal is enhanced in the subsequent reference period (2050-2100) with models showing a precipitation decrease ranging from roughly $-2 \%$ according to RCP2.6 to about $-20 \%$ for RCP8.5 and A2 and $-25 \%$ for $\mathrm{A} 1 \mathrm{~B}$.

Scenario B1 is the generally milder in terms of impact on water availability B1 is projected. Especially for the period 2000-2050, while precipitation remains practically the same to the baseline period, water availability is projected to increase. The increase in water availability can be attributed to shorter precipitation periods around the winter season (combined with less evaporation) and higher precipitation events resulting to increased winter flows. Specific water engineering is necessary for the retention and storage of the ephemeral flows. This is not only the case for the $\mathrm{B} 1$ scenario as the shortage of rainy period is a common characteristic of all the projections. Generally projections under A1B scenario foresee more pronounced precipitation and water availability decrease when compared to even "higher-end" scenarios like A2 and RCP8.5 (Table 4). This could be attributed to the spatial scale of climate models used for each scenario (RCMs for A1B and GCMs for all the rest of scenarios). For the second reference period 2050-2100 the deterioration of water availability is more pronounced and robustly projected for all scenarios, ranging from $-10 \%$ for $\mathrm{B} 1$ and $-19.8 \%$ for RCP2.6 mild scenarios to about $-30,-40$ and $-50 \%$ for the RCP8.5, A2 and A1B scenarios, respectively.

Relative changes from multi-model projections for the 2050-2100 period and for each SRES and RCP are plotted against the corresponding radiative forcing of the scenario at the end of the $21^{\text {st }}$ century in Fig. 5. There is a clear signal of higher temperature change 
Table 4 Summary of projected hydro-meteorological changes for each scenario and future period

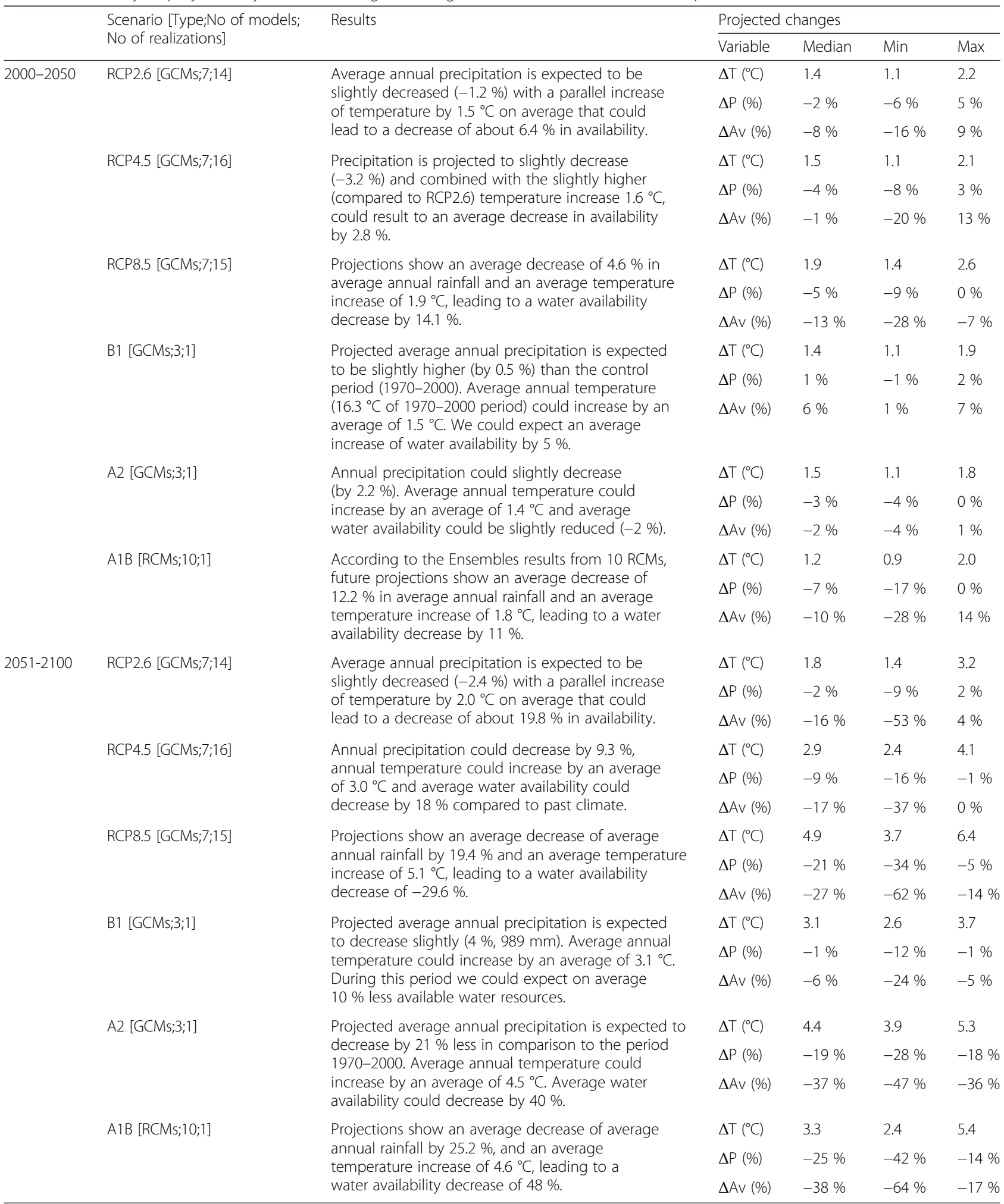

with increased radiative forcing despite the differences on type of models (CGMs or RCMs), number of models and realizations. Regarding the changes in precipitation and water availability for the same period it is worth noting that the decrease of water availability with the increase of radiative forcing is by an average of $10 \%$ 


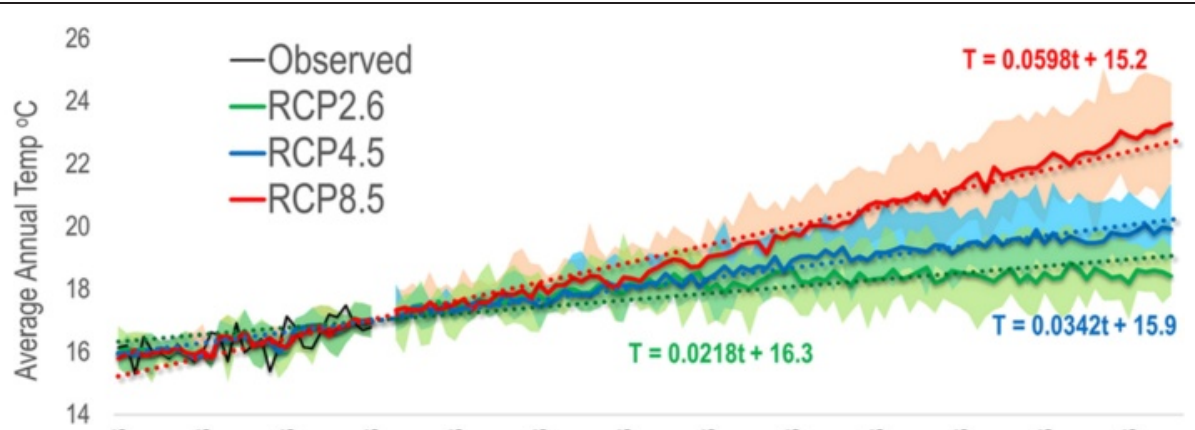

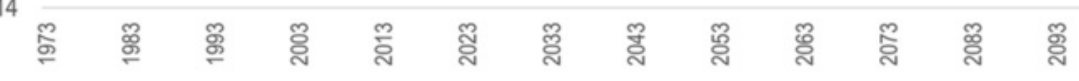
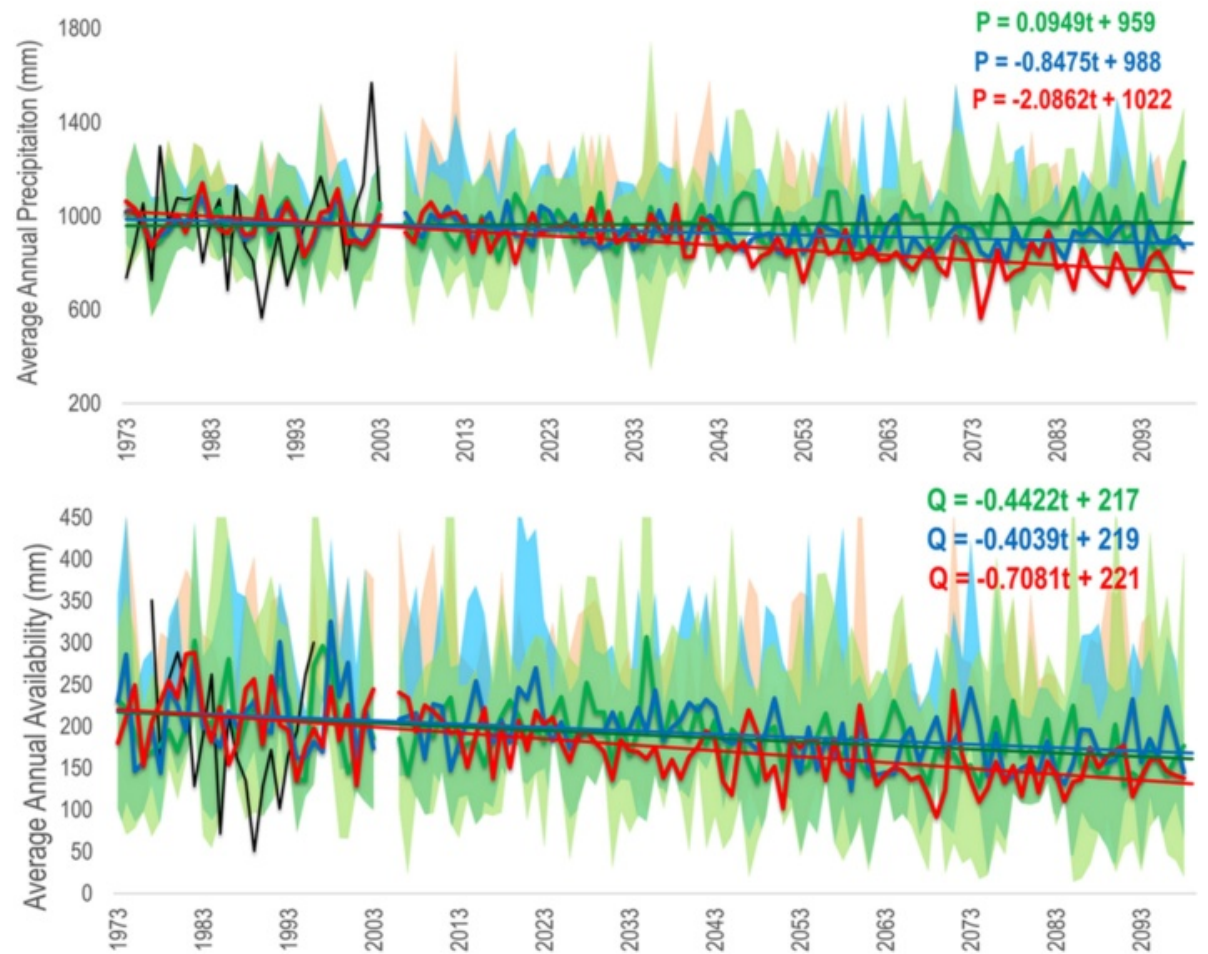

Fig. 4 Upper and middle panels include projections of average annual temperature and precipitation over Crete from a bias adjusted multi-model ensemble and average runoff (bottom panel) over Crete for the three RCPs

enhanced compared to precipitation reduction, reinforcing the assumption that temperature increase is an important factor of the hydrological change, and is a key factor for the "low-end" scenarios. The same does not apply for the first reference period in which the change in the water availability is almost equal to the change in precipitation (not shown here). It is however important to state that the range of projections for $\mathrm{A} 2$ and $\mathrm{B} 1$ is limited compared to the rest of the scenarios due to the limited number of models used (three).

\section{Decadal predictions}

The need of periodic update (every six year) of the water management plans lead to the examination of the ability of decadal prediction experiments to reproduce temperature and precipitation parameters over Crete based on a set of 439 realizations from Earth System Models (ESMs) within the CMIP5 protocol. A summary of simple performance metrics like mean, standard deviation and coefficient of variation of monthly mean precipitation and temperature values are included in Table 5. It is obvious that decadal predictions are highly biased following their imperfect climatology (Meehl et al. 2009) over the study area. Biases are ranging from -55 to $-70 \%$ for precipitation and from 0.4 to $2.5{ }^{\circ} \mathrm{C}$ for temperature. These biases could be caused by imperfections in sub-grid scale climate model conceptualizations and the still course spatial resolution and were removed by applying the simple method described in section Bias adjustment. 

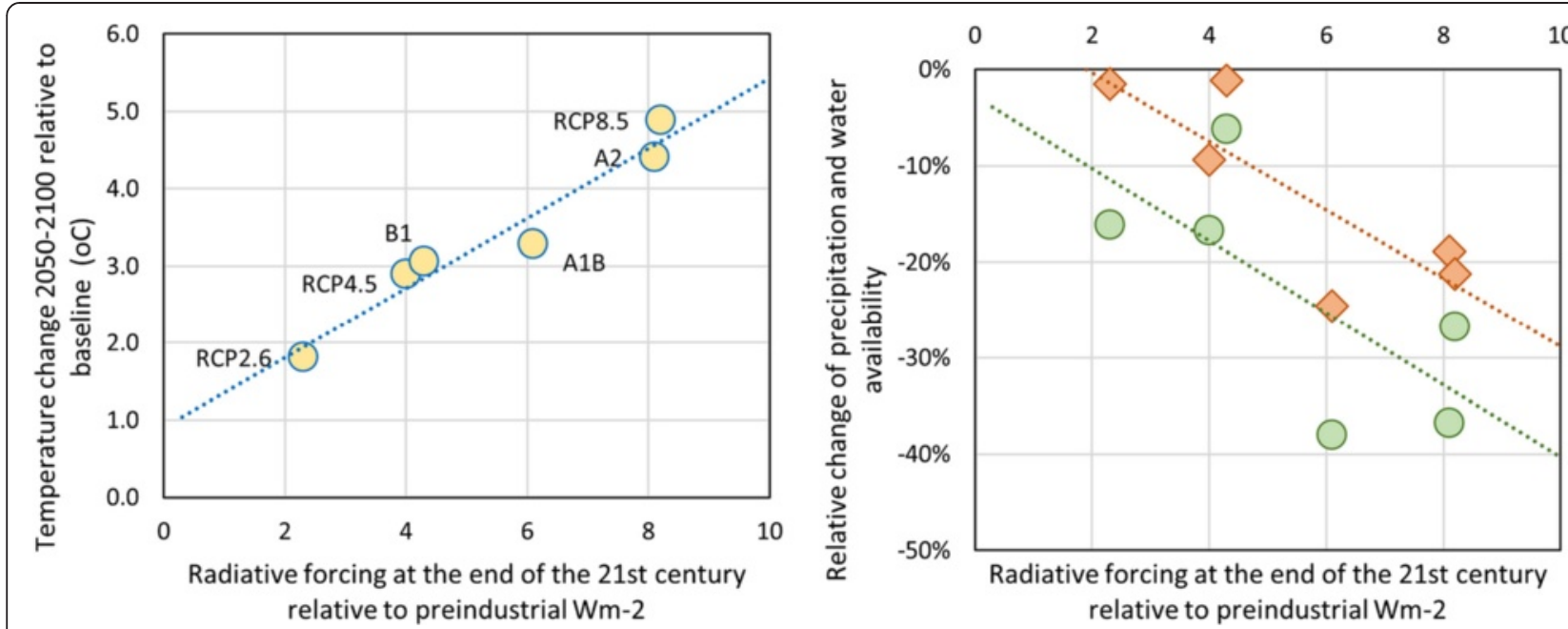

Fig. 5 Average temperature (left), precipitation (right panel-orange markers) and water availability (right panel-green markers) response to radiative forcing (RCPS and SRES) by the end of the $21^{\text {st }}$ century

Figure 6 presents the correlation coefficients for annual precipitation and temperature over Crete from each CMIP5 model decadal predictions as a function of lead time. Period of 4 years duration at all available lead times with respect to start of the prediction period were examined (as a common practice in decadal skill examination (Ho et al. 2012; Eade et al. 2014; Kim et al. 2012)). Multirealization skill in terms of correlation with observation exceeds the skill of the best available realization so timeseries of multi-realizations mean annual precipitation and temperature were used for each contributing model. CMCC-CM exhibits the best overall correlation performance for precipitation despite the fewer realizations and this could be attributed to the specific full value initialization technique that was adopted using the CMCCINV ocean synthesis. Correlation coefficients for this model (CMCC-CM) are higher for lead times of 3-6 and 4-7 years (around 0.5) and of the order of 0.3 for three out of five models at lead time $2-5$ years. Correlations skill is higher for temperature and especially for CNRM-CM5 that is improved for short and medium lead times. The high performance of CNRM-CM5 could come from externally forced initial states of constrained SST from a flux correction.

In order to answer the question: What was the performance of the prediction over random chance?, bias adjusted results were examined for the ability to capture number of "wet" and "dry" years and number of "hot" and "cold" years (Table 6). Years with total annual precipitation below the $20^{\text {th }}$ percentile $(<780 \mathrm{~mm})$ of the control period 1970-2000 were defined as "Dry", while years over the $80^{\text {th }}$ percentile $(>1100 \mathrm{~mm})$ were defined as "Wet" (for both observations and bias adjusted model outputs). Similarly, years with average annual temperature below the $20^{\text {th }}$ percentile $\left(<15.9{ }^{\circ} \mathrm{C}\right)$ of the control period 1970-2000 were defined as "Cold", while years

Table 5 Summary of the average skill of decadal experiments for precipitation and temperature derived from monthly mean values

\begin{tabular}{|c|c|c|c|c|c|c|c|}
\hline \multirow[t]{6}{*}{ Precipitation } & OBS & Metric & CMCC-CM & CNRM-CM5 & EC-EARTH & HadCM3 & MPI-ESM \\
\hline & & CV-DEV & 0.125 & -0.204 & 0.047 & -0.025 & 0.166 \\
\hline & 1.041 & $\mathrm{CV}$ & 1.235 & 0.867 & 1.132 & 1.087 & 1.233 \\
\hline & 83.4 & STDEV & 29.6 & 32.1 & 36.1 & 35.3 & 32.7 \\
\hline & 80.1 & Mean & 23.9 & 37.1 & 31.9 & 32.5 & 26.5 \\
\hline & & Bias & -56.2 & -44.7 & -48.4 & -54.3 & -55.2 \\
\hline \multirow[t]{6}{*}{ Temperature } & OBS & Metric & CMCC-CM & CNRM-CM & EC-EARTH & HadCM3 & MPI-ESM \\
\hline & & CV-DEV & -0.146 & -0.066 & -0.156 & -0.149 & -0.162 \\
\hline & 0.350 & $\mathrm{CV}$ & 0.214 & 0.295 & 0.204 & 0.211 & 0.198 \\
\hline & 5.6 & STDEV & 3.6 & 5.5 & 3.4 & 3.9 & 3.7 \\
\hline & 16.1 & Mean & 16.8 & 18.8 & 16.8 & 18.4 & 18.8 \\
\hline & & Bias & 0.5 & 2.4 & 0.4 & 2.1 & 2.5 \\
\hline
\end{tabular}




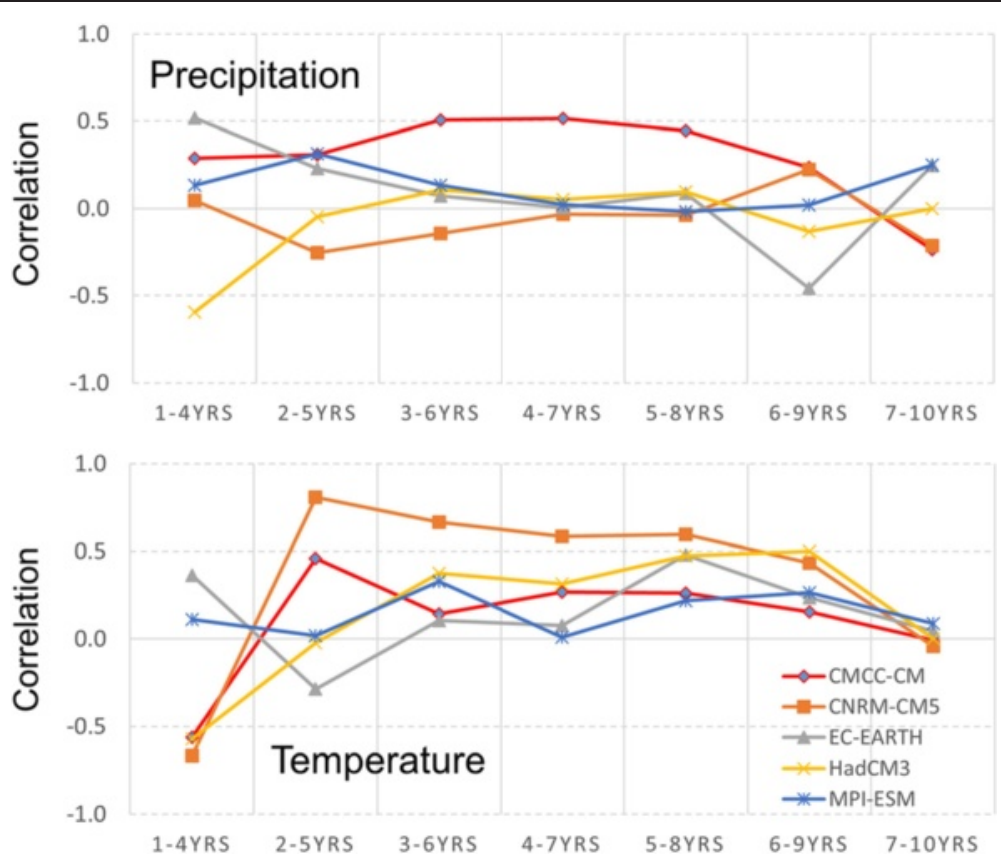

Fig. 6 Correlation coefficients for annual precipitation and temperature over Crete from each CMIP5 model decadal predictions (average of realizations) as a function of lead time (years)

over the $80^{\text {th }}$ percentile $\left(>16.7^{\circ} \mathrm{C}\right)$ were defined as "Hot". EC-Earth and HadCM3 shows the ability to more realistically predict the number of "wet" and "dry" years on average. Especially for the 1990-2000 high variability decade, HadCM3 was able to predict 3 of 4 observed wet years and 2 of 3 observed dry years. Similarly for temperature HadCM3 has the better performance in predicting "hot" years on average but not the same applies for "cold" years.

The low resolution of the models when compared to the size of the study area could be one of the main reasons of the biases in decadal predictions. Experiments with a horizontal resolution of the order of one or more decimal degrees cannot capture and resolve local scale processes. Despite these limitations, results presented above shows signals of valuable information in practice. Therefore, $d y-$ namical downscaling of the large scale signals provided by the GCMs could potentially reveal improved prediction skill at decadal time scales.

\section{Precipitation extremes: annual exceedance probability of maximum daily precipitation and higher percentiles}

Projected changes in precipitation extremes were communicated in terms of changes in Annual Exceedance Probability (AEP) based on annual maximum precipitation values. Annual Exceedance from $5 \%$ Probability (20 years return period) up to $2 \%$ (50 years return period events) were estimated at station level based on daily precipitation records at 52 locations over Crete (observations), control period (1970-2000) runs using the $25 \mathrm{~km}$ RCMs from ENSEMBLES project and three projection periods (2010-2040, 2041-2070, 2071-2100). Based on 30 years long time-series it is safe to extrapolate up to $2 \% \operatorname{AEP}$ (50 years return period) and results presented below are based on these estimates. Generalized Extreme Value (GEV) distribution was used to model the annual rainfall maxima.

Projections were obtained from the most complete in terms of models number and more detailed in terms of spatial resolution simulations of ENSEMBLES FP6 project (Van der Linden 2009), forced using observed GHG greenhouse gas and aerosol concentrations until 2000 and SRES A1B concentrations scenario until 2100. Simulations from 10 RCMs were retrieved and adjusted for biases at station level against daily precipitation records using a multi-segment bias correction method that performs better especially for extremes values, compared to methods using one theoretical distribution to fit the entire CDF or distribution free methods. The coarse density of the station network over the western part of Crete results to biased results based on a few stations.

The effectiveness of the bias correction method to realistically adjust climate modelled precipitation maxima close to observations is presented in Fig. 7 (three upper panels). The average bias of 50 years return period extreme values ( $2 \%$ AEP) based on raw RCMs outputs compared to the ones estimated from observations was underestimated by more than $50 \%(-87 \mathrm{~mm}$ results not shown here and ranging from $-19 \mathrm{~mm}$ to $-221 \mathrm{~mm}$ among the 52 stations) and with the application of the 
Table 6 Decadal experiments: number of "wet" and "dry" years and number of "hot" and "cold" years

\begin{tabular}{|c|c|c|c|c|c|c|c|c|}
\hline & & & 1970 & 1975 & 1980 & 1985 & 1990 & 1995 \\
\hline \multirow[t]{12}{*}{ Precipitation } & WET(\#y) & OBS & & 0 & 2 & 3 & 4 & 1 \\
\hline & & CMCC-CM & & 1 & 3 & 2 & 2 & 3 \\
\hline & & CNRM-CM5 & & 1 & 2 & 3 & 2 & 3 \\
\hline & & EC-Earth-KNMI & & 1 & 2 & 3 & 2 & 1 \\
\hline & & HadCM3 & & 1 & 2 & 2 & 3 & 2 \\
\hline & & MPI-ESM-LR & & 2 & 1 & 2 & 2 & 3 \\
\hline & $\mathrm{DRY}(\# \mathrm{y})$ & OBS & & 0 & 2 & 2 & 3 & 1 \\
\hline & & CMCC-CM & & 0 & 1 & 2 & 1 & 1 \\
\hline & & CNRM-CM5 & & 0 & 1 & 2 & 2 & 1 \\
\hline & & EC-Earth-KNMI & & 0 & 2 & 2 & 2 & 1 \\
\hline & & HadCM3 & & 0 & 1 & 2 & 2 & 1 \\
\hline & & MPI-ESM-LR & & 0 & 1 & 1 & 2 & 1 \\
\hline \multirow[t]{12}{*}{ Temperature } & COLD(\#y) & OBS & 0 & 0 & 1 & 1 & 3 & 2 \\
\hline & & CMCC-CM & 1 & 1 & 1 & 2 & 3 & 1 \\
\hline & & CNRM-CM5 & 1 & 1 & 1 & 2 & 1 & 2 \\
\hline & & EC-Earth-KNMI & 1 & 2 & 1 & 3 & 2 & 2 \\
\hline & & HadCM3 & 1 & 0 & 1 & 2 & 1 & 2 \\
\hline & & MPI-ESM-LR & 0 & 1 & 2 & 1 & 4 & 1 \\
\hline & HOT(\#y) & OBS & 1 & 2 & 2 & 2 & 3 & 2 \\
\hline & & CMCC-CM & 1 & 1 & 0 & 1 & 4 & 2 \\
\hline & & CNRM-CM5 & 1 & 1 & 2 & 3 & 2 & 4 \\
\hline & & EC-Earth-KNMI & 1 & 1 & 1 & 1 & 3 & 3 \\
\hline & & HadCM3 & 0 & 2 & 3 & 2 & 4 & 2 \\
\hline & & MPI-ESM-LR & 2 & 1 & 1 & 2 & 3 & 1 \\
\hline
\end{tabular}

adjustment the underestimation dropped to $5 \%$ (remaining average bias of $8-\mathrm{mm}$ ranging from $-04 \mathrm{~mm}$ to $+25 \mathrm{~mm}$ among the 52 stations).

A substantial increase of the $2 \%$ AEP is projected for all future periods. An average increase of over $40 \%$ (over $65 \mathrm{~mm}$ ) is projected from the average of the 10 RCMs under A1B scenario ranging from $9 \mathrm{~mm}$ to $175 \mathrm{~mm}$ among the 52 stations (Fig. 7 lower panels). A similar but somehow smaller increase in average $2 \%$ AEP is projected for the subsequent periods. Extreme daily precipitation of $2 \%$ AEP could increase over $30 \%$ (50 mm) for the 2041-2070 period (ranging from $18 \mathrm{~mm}$ to $230 \mathrm{~mm}$ among the 52 stations) and over $25 \%$ (40 mm) during the 2071-2100 period (ranging from $36 \mathrm{~mm}$ to $236 \mathrm{~mm}$ among the 52 stations). Although average $2 \%$ AEP is decreasing moving from 20102040 to $2041-2070$ and 2071-2100, the $2 \%$ AEP variability among the 52 station locations is continuously increasing. Figure 8 illustrates the spread of the results in the form of box plots. Results of 2, 3.3 and $5 \%$ AEP, that correspond to 50, 30 and 20 years return period, respectively, from all 10 bias adjusted ENSEMBLES RCMs and for all 52 raingauges are summarized in this figure, for the three projection periods under A1B scenario. Mean, median and spread of modeled values (interquartile and minimum-maximum) for the baseline period are close to the corresponding from observations for all AEPs. The median of all projected AEP values is increasing with consecutive periods. The range of projections is also broader with higher minimum values and remarkably higher maximum.

Precipitation maxima were also expressed in terms of extreme percentiles and more specifically the 99.9-ile\%. This percentile for a 30 years long time series of daily precipitation corresponds to a threshold of the 11 maximum values, roughly. The value of this percentile based on daily precipitation records of the 52 stations is described by an average of $89 \mathrm{~mm}$ ranging from $59 \mathrm{~mm}$ over central south Crete to $184 \mathrm{~mm}$ over Western Crete. The application of the bias adjustment had similar results to the $2 \%$ AEP. The remaining bias of the average 99.9-ile\% over the 52 stations dropped to about $1 \%$ from an over $55 \%$ average bias $(-50 \mathrm{~mm})$. Projections indicate a similar increase of the $99.9-\mathrm{ile} \%$ values of the order of 9, 8 and $7 \%$ for the 2010-2040, 2041-2070 and 2071-2100 periods, respectively (Fig. 9). The values 

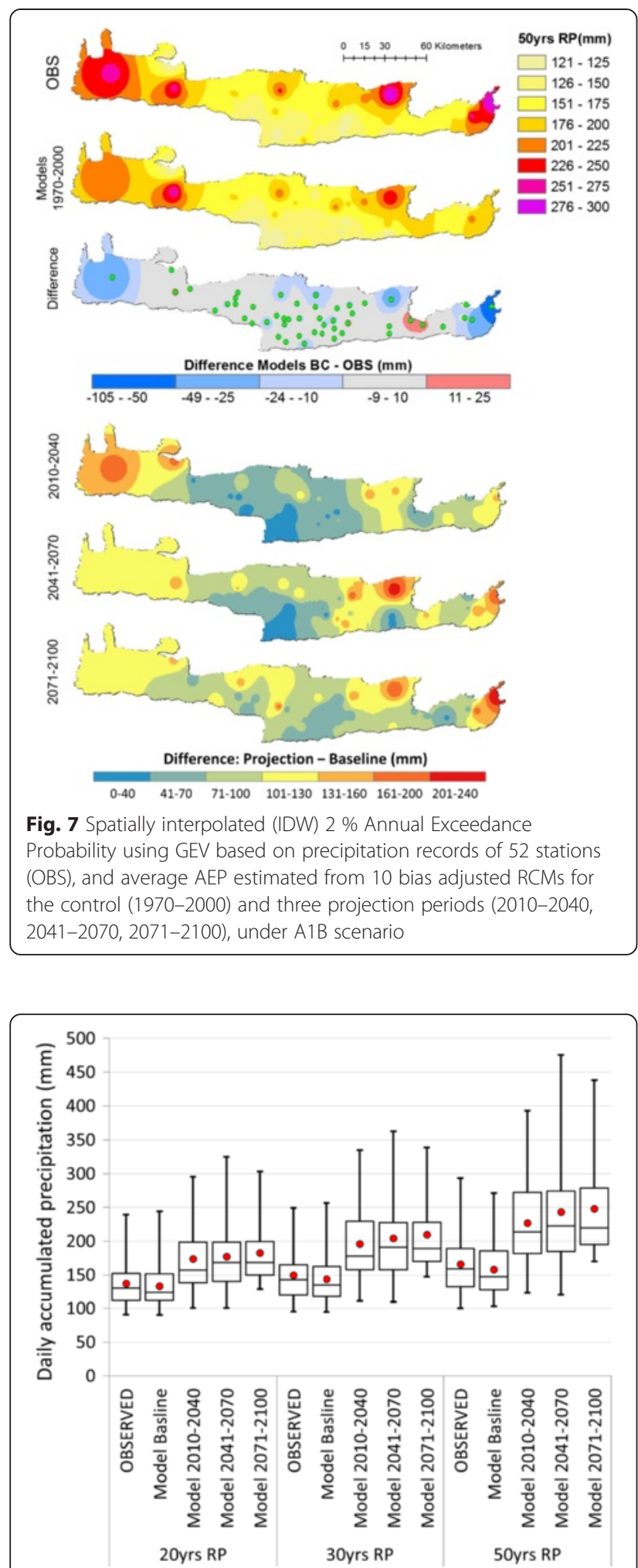

Fig. 8 Aggregated results (box plots) of $2 \%$ (50 year), $3.3 \%$ (30 year) and $5 \%$ (20 year) Annual Excedance probability (Return Period) from the 10 bias adjusted Ensembles RCMs and the 52 gauging station for observations (OBS), the control (1970-2000) and three projection periods (2010-2040, 2041-2070, 2071-2100), under A1B scenario

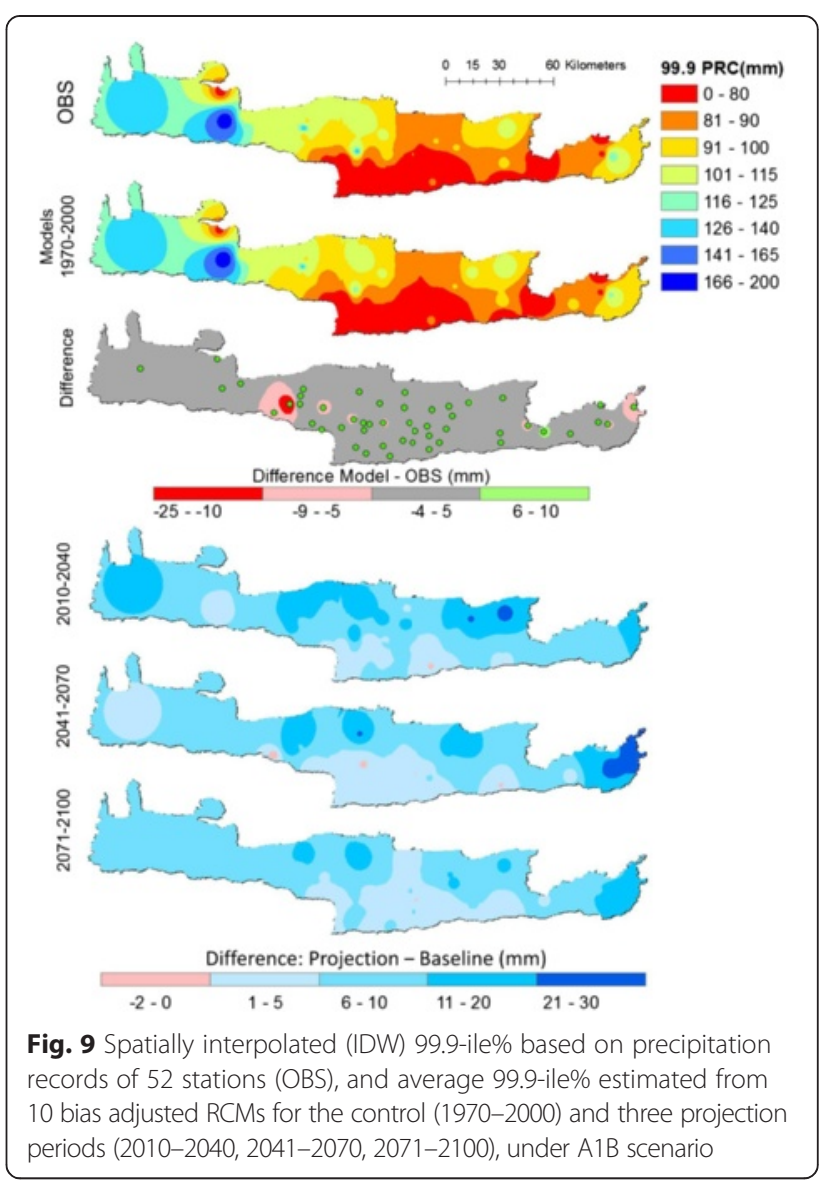

range from a decrease of $2.5 \mathrm{~mm}$ to an increase of $27 \mathrm{~mm}$ among the stations.

\section{Non-hydrostatic high-resolution RCMs experiments}

Simulations for three storm events triggering flash flooding in different parts of Crete were performed by the modelling groups. The events were selected in terms of severity, data availability and location (Fig. 10). A short overview of the events is presented in (Sobolowski et al. (2014).

\section{(i) November 17, 2006 - the Almirida basin flash flood event}

The Almirida watershed is located in the northwest part of the island of Crete. The watershed covers an area of $25 \mathrm{~km}^{2}$ and has a mean slope of $11.9 \%$ with elevation ranging from 5 to $527 \mathrm{~m}$ above sea level. The mean annual precipitation is $648 \mathrm{~mm}$. On 17 October, 2006, a frontal depression in the central Mediterranean moved eastward and crossed the island of Crete mid-day on 17 October 2006 (Tsanis 2008). This depression caused a high intensity short duration heavy rainfall event resulting in a flash flood. Weather radar located less than $25 \mathrm{~km}$ from the watershed provided sparse reflectivity 

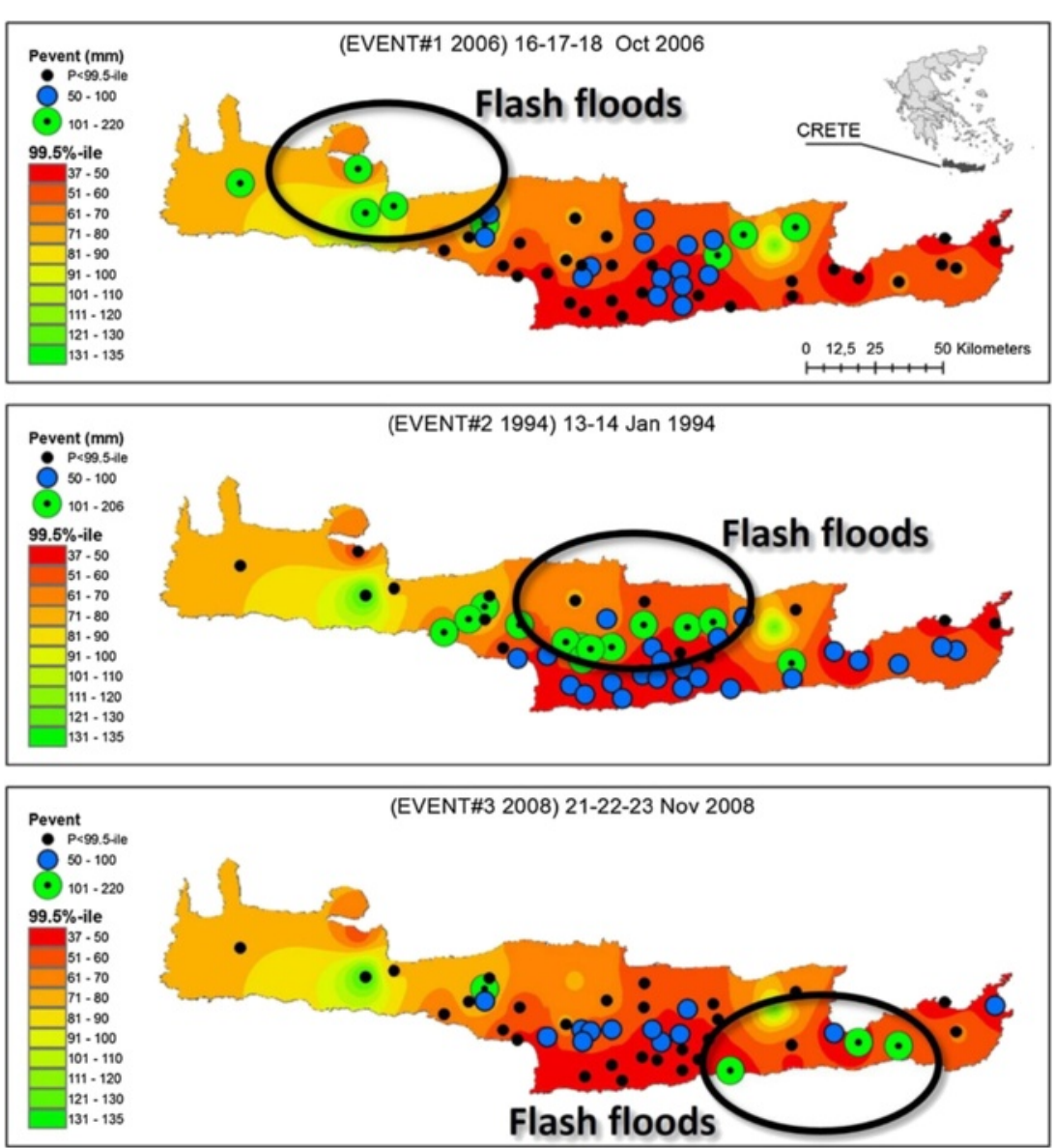

Fig. 10 Three high resolution test cases over Crete. The 99.5-ile\% classified map derived from the interpolation (IDW) of daily precipitation values from 50 stations (with more than 30 gauging years). Black dots indicate precipitation stations with daily accumulated precipitation lower that the 99.5-ile\%. Blue and green dots correspond to stations daily accumulated precipitation over the $99.5-i l e \%$, for two classes of less than $100 \mathrm{~mm}$ and more than $100 \mathrm{~mm}$, respectively

data during the event due to power outages in the area (Daliakopoulos \& Tsanis 2012). The neighboring rain gauge of Souda Bay $(16 \mathrm{~km})$ recorded a maximum hourly precipitation of $25.2 \mathrm{~mm}$ and a daily gauge (Kalives) located just $3 \mathrm{~km}$ from the watershed recorded $220 \mathrm{~mm}$, far exceeding the $1 \%$ AEP (100 year return period) of the particular station (Koutroulis et al. 2010). Hydrologic analysis showed that this flash flood event produced an estimated peak flow on the order of $120 \mathrm{~m}^{3} / \mathrm{s}$ (Tsanis et al. 2014), which corresponds to a specific peak discharge of $5 \mathrm{~m}^{3} / \mathrm{s} / \mathrm{km}^{2}$ (Gaume et al. 2009). This extreme event led to the loss of one life and over $€ 1 \mathrm{M}$ in damages in Almirida alone and a total damage toll of approximately $€ 3 \mathrm{M}$.

This storm event was simulated by the HCLIM, HARMONIE and WRF NHRMs. The location of the storm over Western Crete was adequately captured by all three models. Observed accumulated precipitation (up to $330 \mathrm{~mm}$ ) for the three days 16-18 October 2006 was simulated more realistically by WRF model in terms of rainfall height. HCLIM and HARMONIE resulted in less rainfall compared to observations. The temporal evolution of the precipitation was captured by all models but more realistically in terms of rainfall amount by WRF, for the flood nearby area. Simulations of $+2{ }^{\circ} \mathrm{C}$ resulted to increased precipitation totals for the Souda-airport and Chania-Halepa stations that are located relatively close to the most impacted flood area. The relative increase for Souda station ranges from 12 to $58 \%$ for total precipitation and from 18 to $210 \%$ for hourly precipitation intensity depending on the model (Fig. 11).

WRF simulation resulted to total precipitation of more than double in comparison to the HCLIM and HARMONIE models. HARMONIE model simulates $25 \%$ more total precipitation at basin level for a warmer climate of $2{ }^{\circ} \mathrm{C}$, while HCLIM results to $17 \%$ and WRF to $1 \%$ (Table 7) higher precipitation that would probably result to more severe flooding conditions. 


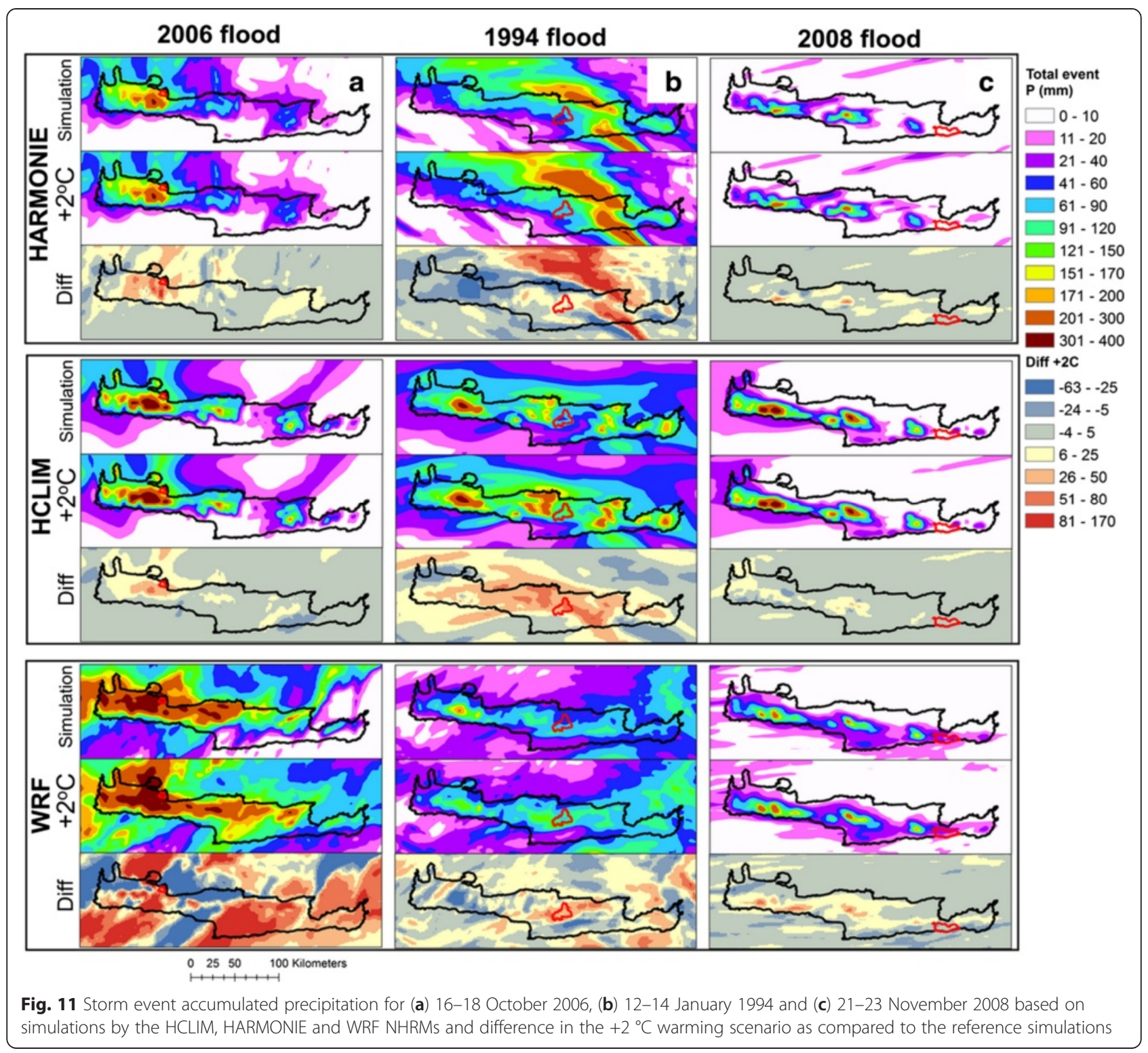

(ii) January 13, 1994 - the Giofiros basin flash flood event

The Giofiros basin is located in North-Central Crete and occupies an area of $186 \mathrm{~km}^{2}$. The Giofiros basin has a seasonal flow during the wet winter period (December to March), when the most of the mean annual rainfall of $827 \mathrm{~mm}$ occurs. On January, 1994, a frontal depression in the south-eastern Mediterranean moved eastward then north crossing the island of Crete (Koutroulis \& Tsanis 2010). On the $13^{\text {th }}$ January 1994 around 1500 UTC, the intensity of the light precipitation that saturated Giofiros soils during the previous days increased. The warm air mass with high dew point, southwest-northeast flow was primarily blocked by the Psiloritis Mountains' steep topography. The air mass was forced to higher elevations, cooled and produced high rates of precipitation of up to $37 \mathrm{~mm} / \mathrm{h}$ at Ag. Varvara station (uphill). A maximum $5 \mathrm{~h}$ accumulated precipitation of $123 \mathrm{~mm}$ was recorded at 2100 UTC. This extreme rainfall eventually stopped at 2400 UTC and lasted almost 9 h, triggering a flash flood. The resulting flash flood had catastrophic impacts on the Giofiros basin. Houses located near the coast were flooded leaving 49 people homeless. The single most adverse effect of the flood was the damage caused to the city's wastewater treatment plant, which was still under construction at the time of the flood. Many of the concrete tanks were rendered inoperable or were completely destroyed by the force of the flood wave.

The location of the storm over central Crete was fairly captured by all three models. Observed accumulated precipitation (up to $200 \mathrm{~mm}$ ) for the three days 12-14 January 1994 (Fig. 11) was underestimated by all models. HCLIM and HARMONIE resulted in less rainfall 
Table 7 Spatialy aggregated information of mean, max and min precipitation and corresponding differences at basin scale (impacted area) and whole island level for each flood event

\begin{tabular}{|c|c|c|c|c|c|c|c|}
\hline & & 2006 & & 1994 & & 2008 & \\
\hline & & Alimirida & Crete & Giofiros & Crete & lerapetra & Crete \\
\hline HARMONIE & Mean Simulation & 123.3 & 47.5 & 61.0 & 76.4 & 5.0 & 19.9 \\
\hline & Max Simulation & 140.2 & 255.9 & 85.8 & 240.0 & 19.8 & 244.5 \\
\hline & Min Simulation & 116.6 & 0.0 & 38.1 & 6.2 & 1.4 & 0.0 \\
\hline & Mean $+2 C$ & 154.7 & 56.5 & 72.1 & 79.0 & 7.0 & 24.0 \\
\hline & Max $+2 C$ & 166.8 & 334.6 & 96.2 & 293.0 & 24.0 & 306.3 \\
\hline & Min $+2 C$ & 142.7 & 0.1 & 45.6 & 1.2 & 2.5 & 0.0 \\
\hline & Diff Mean & 31.3 & 9.0 & 11.2 & 2.6 & 2.1 & 4.1 \\
\hline & Diff Max & 44.2 & 113.9 & 22.7 & 142.2 & 5.6 & 77.8 \\
\hline & Diff Min & 16.2 & -19.4 & 0.0 & -58.7 & 0.6 & -17.3 \\
\hline HCLIM & Mean Simulation & 150.5 & 72.1 & 69.2 & 94.1 & 7.0 & 43.9 \\
\hline & Max Simulation & 171.1 & 484.6 & 93.0 & 352.9 & 67.5 & 420.6 \\
\hline & Min Simulation & 129.8 & 0.3 & 47.0 & 14.2 & 0.0 & 0.0 \\
\hline & Mean $+2 C$ & 175.7 & 76.5 & 113.7 & 119.2 & 12.1 & 46.3 \\
\hline & $\operatorname{Max}+2 \mathrm{C}$ & 199.7 & 546.3 & 145.9 & 382.1 & 69.4 & 435.5 \\
\hline & Min $+2 C$ & 145.9 & 0.4 & 81.3 & 14.2 & 0.1 & 0.0 \\
\hline & Diff Mean & 25.2 & 4.4 & 44.5 & 25.1 & 0.5 & 2.4 \\
\hline & Diff Max & 33.9 & 61.8 & 71.5 & 81.3 & 2.7 & 29.2 \\
\hline & Diff Min & 16.0 & -16.8 & 5.8 & -14.9 & -0.1 & -22.2 \\
\hline WRF & Mean Simulation & 354.6 & 149.9 & 63.8 & 62.4 & 23.4 & 32.1 \\
\hline & Max Simulation & 370.8 & 559.2 & 97.3 & 217.1 & 47.0 & 253.8 \\
\hline & Min Simulation & 308.1 & 0.3 & 44.2 & 5.4 & 15.2 & 0.3 \\
\hline & Mean $+2 C$ & 359.9 & 189.8 & 103.3 & 70.6 & 21.1 & 38.2 \\
\hline & Max $+2 C$ & 404.2 & 660.7 & 158.5 & 190.4 & 46.0 & 301.2 \\
\hline & $\operatorname{Min}+2 C$ & 295.6 & 28.5 & 70.3 & 5.5 & 10.8 & 0.2 \\
\hline & Diff Mean & 5.3 & 39.9 & 39.5 & 8.2 & -2.3 & 6.1 \\
\hline & Diff Max & 65.9 & 312.6 & 65.8 & 65.8 & 5.0 & 73.8 \\
\hline & Diff Min & -57.2 & -172.3 & 19.7 & -90.5 & -8.1 & -28.8 \\
\hline
\end{tabular}

compared to observations as the case of 2006. The lower panels of the Fig. 11 shows the difference in the $+2{ }^{\circ} \mathrm{C}$ warming scenario as compared to the reference simulations. Especially for the uphill stations of the flood impacted watershed, simulations result to higher precipitation totals ranging from 5 to $55 \%$ depending on station and model. All simulations resulted to similar total basin precipitation estimations of the order of $60 \mathrm{~mm}$ to $70 \mathrm{~mm}$. HARMONIE model simulates $18 \%$ more total precipitation at basin level for a warmer climate of $2{ }^{\circ} \mathrm{C}$, while HCLIM results to $64 \%$ and WRF to $62 \%$ higher precipitation Table 7.

\section{(iii) November 22, 2008 - the lerapetra flash flood event}

The Ierapetra region, located in the Southeast of Crete is an area of high agricultural and tourism activity. The average annual precipitation $(440 \mathrm{~mm})$ is significantly lower compared to the western part of the island. The late autumn event of the 22th of November 2008 with an overall duration of $17 \mathrm{~h}$ affected mainly the eastern and central part of the island of Crete, causing extensive damage to property and infrastructure (Koutroulis et al. 2012). The closest synoptic scale atmospheric system was a strong, closed, intense depression of $988 \mathrm{hPa}$ centered over southern Serbia at 0600 UTC 22 November (time of flood event) with an extended effective radius of $5.28^{\circ}$ and a depth of $6.4 \mathrm{hPa} /$ degree (Iordanidou et al. 2013). This closed system moved over northern Greece at 1200 UTC 22 November with the same intensity and dissipated within the next few hours. The accumulated rainfall from a nearby station was $73.8 \mathrm{~mm}$ and the maximum 10 min recorded precipitation was $12.4 \mathrm{~mm}$. Exceptional lightning activity was also recorded during the evolution of the storm. The location of the storm over eastern Crete was not captured the models. Rainfall 
occurrence was better captured over the western and central part of Crete. Observed accumulated precipitation (up to $210 \mathrm{~mm}$ ) for the three days 21-23 November 2008 (Fig. 11) was largely underestimated by all models. WRF model, although underestimated precipitation height, proved efficient in capturing the temporal evolution of the precipitation at the Ierapetra station located near the flood location. All simulations except WRF resulted to increase in total precipitation at watershed level estimations due to a warmer climate (Table 7).

\section{Conclusions}

Despite limitations and uncertainties, this study uses climate change hydro-meteorological impact datasets developed in several European Commission funded projects, providing local water resources management authority with a glimpse into a very plausible future where the quantitative impact of changing climate on water availability and hydrological extremes can be substantial. These results were collectively reported to the local water managing authority trying to meet the information needs in the context of a user-provider interaction.

Updated basin scale climate information was delivered to the user, information that is useful in prioritizing certain water resources related infrastructure development. A robust signal of water scarcity is projected for all the scenarios. According to the Water Directorate, the planned development policy of new water resources engineering is very closely connected with the growth of new irrigated areas leading to an increase of irrigation demand. The conclusion is that an alternative policy of development of new infrastructure should be adapted. This policy should not only give priority to the increase of irrigated areas, but should also assist in the practice of the existing irrigated areas with parallel evaluation of plans for newly irrigated areas. Long term projections indicate shorter precipitation periods around the winter season (combined with less evaporation) and higher precipitation events resulting to increased winter flows. It emerges that the inability to control large outflow quantities that runoff into the sea, despite recent improvements, remains a problem despite the growth of an abundance of infrastructure aiming to store winter spring and stream flows.

Regarding decadal projections, the coarse resolution of ESMs compared to the extent of the study area, cannot describe the local precipitation regime probably due to failure in capturing small scale processes. The bias is ranging from -55 to $-70 \%$ and could be caused by imperfections in sub-grid scale climate model conceptualizations. The relatively high correlation skill of specific models and the ability to capture the number of "wet" and "dry" years on average are encouraging for further investigation of decadal predictions. Dynamical downscaling of these experiments is proposed to be performed and evaluated for their applicability on short term management planning.

A robust increasing signal of daily precipitation maxima under $\mathrm{A} 1 \mathrm{~B}$ emission scenarios is projected from a set of 10 RCMs. Projected changes in precipitation extremes were communicated in terms of changes in Annual Exceedance Probability (AEP) based on annual maximum precipitation values and in terms of extreme percentiles and more specifically the 99.9-ile\%. A substantial increase of the $2 \%$ AEP (50 years return period daily precipitation maxima) is projected for all future periods by an average of almost $40 \%$ (over $65 \mathrm{~mm}$ ) ranging from 9 to $236 \mathrm{~mm}$ among the 52 stations analysed. Projections indicate a similar increase of the $99.9-$ ile\% values of the order of $8 \%$.

Three present day extreme events over the island of Crete were simulating with the use of Non-hydrostatic high-resolution RCMs by the modelling groups of SMHI, UNI and KNMI. These events were also simulated under conditions of a warmer climate $\left(+2{ }^{\circ} \mathrm{C}\right)$. Simulations proved to be sufficiently efficient in realistic capturing historical storm events and thus valuable in impact modelling. Historical storm events over Crete, could produce significantly higher precipitation accumulations and intensities in a warmer climate.

Summarizing, the main findings that should be communicated are:

- A robust signal of temperature increase and precipitation decrease is projected for all the pathways and scenarios resulting to a severe decrease of water availability.

- A promising sign of predictability from decadal prediction experiments that deserves further examination through dynamical downscaling.

- A significant increase of the $2 \%$ Annual Exceedance Probability in maximum daily precipitation is projected for all future periods over the island of Crete.

- Non-hydrostatic high-resolution RCMs proved to be sufficiently efficient in realistic capturing storm events and thus valuable in impact modelling.

- Historical storm events over Crete could produce significantly higher precipitation accumulations and intensities in a warmer climate.

It is considered essential to resolve the increasingly severe water problems facing the island by implementing strategic policies using integrated water management systems. User tailored climate services together with the 
hydrological information services should be co-designed with the local key-stakeholders. This is a necessity because it represents the requirement for proper management of water resources including extremes that will lead to a better infrastructure planning for a sustainable future.

\section{Competing interests}

The authors declare that they have no competing interests.

\section{Authors' contributions}

AGK and MGG performed data analysis and completed the first draft of the manuscript with oversight by IKT. DJ provided datasets and guidance on analysis. All authors read and approved the final manuscript.

\section{Acknowledgement}

The financial support of this work has been provided by the European Commission through the ECLISE, COMBINE and IMPACT2C FP7 and WATCH FP6 projects. We are also grateful to the modeling teams of (Royal Netherlands Meteorological Institute, Climate Service Center, Uni Research and Swedish Meteorological and Hydrological Institute) for performing the set of experiments with NHRMs. The ENSEMBLES data used in this work was funded by the EU FP6 Integrated Project ENSEMBLES (Contract number 505539) whose support is gratefully acknowledged. We also acknowledge the World Climate Research Programme's Working Group on Coupled Modelling, which is responsible for CMIP, and we thank the climate modeling groups (listed in Table 2 of this paper) for producing and making available their model output. For CMIP the U.S. Department of Energy's Program for Climate Model Diagnosis and Intercomparison provides coordinating support and led development of software infrastructure in partnership with the Global Organization for Earth System Science Portals. We also thank the two anonymous reviewers whose comments have improved the paper.

\section{Author details}

'Department of Environmental Engineering, Technical University of Crete, Chania, Greece. ${ }^{2}$ Department of Civil Engineering, McMaster University, Hamilton, ON, Canada. ${ }^{3}$ Climate Service Centre Germany (GERICS), Helmholtz-Zentrum Geesthacht, Hamburg, Germany.

Received: 4 November 2014 Accepted: 18 November 2015

\section{Published online: 24 November 2015}

\section{References}

Andrews T, Gregory JM, Webb MJ, Taylor KE (2012) Forcing, feedbacks and climate sensitivity in CMIP5 coupled atmosphere-ocean climate models. Geophys Res Lett 39:n/a-n/a. doi:10.1029/2012GL051607

Arnell NW, van Vuuren DP, Isaac M (2011) The implications of climate policy for the impacts of climate change on global water resources. Glob Environ Chang 21:592-603. doi:10.1016/j.gloenvcha.2011.01.015

Bellucci A, Masina S, DiPietro P, Navarra A (2007) Using temperature-salinity relations in a global ocean implementation of a multivariate data assimilation scheme. Mon Weather Rev 135:3785-3807. doi:10.1175/2007MWR1821.1

Bentsen M, Bethke I, Debernard JB et al (2013) The Norwegian earth system model, NorESM1-M - Part 1: description and basic evaluation of the physical climate. Geosci Model Dev 6:687-720. doi:10.5194/gmd-6-687-2013

Bokoye A, Bussières L, Cotnoir A et al (2014) Canadian climate services: exploring an appropriate road map to fulfill a growing need. Bull Am Meteorol Soc 95: ES07-ES10. doi:10.1175/BAMS-D-13-00025.1

Christensen OB, Drews M, Christensen JH, Dethloff K, Ketelsen K, Hebestadt I, et al. (2006) The HIRHAM regional climate model version 5 ( $\beta$ ). Techical Rep 6-17

Collins M, Tett SFB, Cooper C (2001) The internal climate variability of HadCM3, a version of the Hadley Centre coupled model without flux adjustments. Clim Dyn 17:61-81. doi:10.1007/s003820000094

Collins M, Booth BBB, Bhaskaran B et al (2010) Climate model errors, feedbacks and forcings: a comparison of perturbed physics and multi-model ensembles. Clim Dyn 36:1737-1766. doi:10.1007/s00382-010-0808-0

Collins WJ, Bellouin N, Doutriaux-Boucher M et al (2011) Development and evaluation of an Earth-System model - HadGEM2. Geosci Model Dev 4:1051-1075. doi:10.5194/gmd-4-1051-2011
Daliakopoulos IN, Tsanis IK (2012) A weather radar data processing module for storm analysis. J Hydroinformatics 14:332. doi:10.2166/hydro.2011.118

Davini P, Cagnazzo C, Fogli PG et al (2013) European blocking and Atlantic jet stream variability in the NCEP/NCAR reanalysis and the CMCC-CMS climate model. Clim Dyn 43:71-85. doi:10.1007/s00382-013-1873-y

Dee DP, Uppala SM, Simmons AJ et al (2011) The ERA-Interim reanalysis: configuration and performance of the data assimilation system. Q J R Meteorol Soc 137:553-597. doi:10.1002/aj.828

Du H, Doblas-Reyes FJ, García-Serrano J et al (2012) Sensitivity of decadal predictions to the initial atmospheric and oceanic perturbations. Clim Dyn 39:2013-2023. doi:10.1007/s00382-011-1285-9

Dufresne J-L, Foujols MA, Denvil S et al (2013) Climate change projections using the IPSL-CM5 Earth System Model: from CMIP3 to CMIP5. Clim Dyn 40:2123-2165. doi:10.1007/s00382-012-1636-1

Eade R, Smith D, Scaife A et al (2014) Do seasonal-to-decadal climate predictions underestimate the predictability of the real world? Geophys Res Lett 41:5620-5628. doi:10.1002/2014GL061146

Eash DA, Barnes KK, Veilleux AG (2013) Methods for Estimating Annual Exceedance-Probability Discharges for Streams in lowa, Based on Data through Water Year 2010

Faysse N, Rinaudo J-D, Bento S et al (2012) Participatory analysis for adaptation to climate change in Mediterranean agricultural systems: possible choices in process design. Reg Environ Chang 14:57-70. doi:10.1007/s10113-012-0362-x

García-Ruiz JM, López-Moreno Jl, Vicente-Serrano SM et al (2011) Mediterranean water resources in a global change scenario. Earth Sci Rev 105:121-139. doi:10.1016/j.earscirev.2011.01.006

Gaume E, Bain V, Bernardara P, Newinger O, Barbuc M, Bateman A et al (2009) A compilation of data on European flash floods. J Hydrol 367:70-78

Giorgi F, Mearns LO (1999) Introduction to special section: Regional Climate Modeling Revisited. J Geophys Res 104:6335. doi:10.1029/98JD02072

Grillakis MG, Koutroulis AG, Tsanis IK (2011) Climate change impact on the hydrology of Spencer Creek watershed in Southern Ontario, Canada. J Hydrol 409:1-19. doi:10.1016/j.jhydrol.2011.06.018

Grillakis MG, Koutroulis AG, Tsanis IK (2013) Multisegment statistical bias correction of daily GCM precipitation output. J Geophys Res Atmos 118:3150-3162. doi:10.1002/jgrd.50323

Guido Z, Hill D, Crimmins M, Ferguson D (2013) Informing decisions with a climate synthesis product: implications for regional climate services. Weather Clim Soc 5:83-92. doi:10.1175/WCAS-D-12-00012.1

Haddeland I, Clark DB, Franssen W et al (2011) Multimodel estimate of the global terrestrial water balance: setup and first results. J Hydrometeorol 12:869-884. doi:10.1175/2011JHM1324.1

Haerter JO, Hagemann S, Moseley C, Piani C (2011) Climate model bias correction and the role of timescales. Hydrol Earth Syst Sci 15:1065-1079. doi:10.5194/hess-15-1065-2011

Hazeleger W, Wang X, Severijns C et al (2011) EC-Earth V2.2: description and validation of a new seamless earth system prediction model. Clim Dyn 39:2611-2629. doi:10.1007/s00382-011-1228-5

Hesselbjerg Christensen J, Kjellström E, Giorgi F et al (2010) Weight assignment in regional climate models. Clim Res 44:179-194

Hewitt C, Mason S, Walland D (2012) The global framework for climate services. Nat Clim Chang 2:831-832. doi:10.1038/nclimate1745

Hewitt C, Buontempo C, Newton P (2013) Using climate predictions to better serve society's needs. EOS Trans Am Geophys Union 94:105-107. doi:10.1002/2013EO110002

Ho CK, Hawkins E, Shaffrey L, Underwood FM (2012) Statistical decadal predictions for sea surface temperatures: a benchmark for dynamical GCM predictions. Clim Dyn 41:917-935. doi:10.1007/s00382-012-1531-9

Hong S-Y, Lim J-OJ (2006) The WRF single-moment 6-class microphysics scheme (WSM6). J Korean Meteor Soc 42:129-151

Interagency Advisory Committee on Water Data (IACWD), 1982. Guidelines for determining flood flow frequency. Bulletin 17B of the Hydrology Subcommittee, OWDC, US Geological Survey, Reston, VA

Iordanidou V, Koutroulis A, Tsanis I, Flocas H (2013) Qualitative Features of Cyclones triggering high precipitation events in the Island of Crete, Eastern Mediterranean. EGU General Assembly Conference Abstracts, Vienna, Austria. Vol. 15. 2013. p. 4410

Jacob D (2001) A note to the simulation of the annual and inter-annual variability of the water budget over the Baltic Sea drainage basin. Meteorol Atmos Phys 77:61-73 
Jaeger EB, Anders I, Lüthi D et al (2008) Analysis of ERA40-driven CLM simulations for Europe. Meteorol Zeitschrift 17:349-367. doi:10.1127/0941-2948/2008/0301

Kim H-M, Webster PJ, Curry JA (2012) Evaluation of short-term climate change prediction in multi-model CMIP5 decadal hindcasts. Geophys Res Lett 39:n/a-n/a. doi:10.1029/2012GL051644

Kjellstrom E, Barring L, Gollvik S, Hansson U et al (2005) A 140-year simulation of European climate with the new version of the Rossby Centre regional atmospheric climate model (RCA3). SMHI, Norrkoping

Kostopoulou E, Giannakopoulos C, Hatzaki M et al (2013) Assessment of climate change extremes over the Eastern Mediterranean and Middle East Region using the Hadley Centre PRECIS Regional Climate Model. In: Helmis CG, Nastos PT (eds) Adv. Meteorol. Climatol. Atmos. Phys. SE - 78, vol 78. Springer, Berlin Heidelberg, pp 547-554

Koutroulis AG, Tsanis IK (2010) A method for estimating flash flood peak discharge in a poorly gauged basin: case study for the 13-14 January 1994 flood, Giofiros basin, Crete, Greece. J Hydrol 385:150-164. doi:10.1016/j.jhydrol.2010.02.012

Koutroulis AG, Tsanis IK, Daliakopoulos IN (2010) Seasonality of floods and their hydrometeorologic characteristics in the island of Crete. J Hydrol 394:90-100. doi:10.1016/j.jhydrol.2010.04.025

Koutroulis AG, Grillakis MG, Tsanis IK et al (2012) Lightning activity, rainfall and flash flooding - occasional or interrelated events? A case study in the island of Crete. Nat Hazards Earth Syst Sci 12:881-891. doi:10.5194/nhess-12-881-2012

Koutroulis AG, Tsanis IK, Daliakopoulos IN, Jacob D (2013) Impact of climate change on water resources status: a case study for Crete Island, Greece. J Hydrol 479:146-158. doi:10.1016/j.jhydrol.2012.11.055

Kröger J, Müller WA, von Storch J-S (2012) Impact of different ocean reanalyses on decadal climate prediction. Clim Dyn 39:795-810 doi:10.1007/s00382-012-1310-7

Lindstedt D, Lind P, Kjellström E, Jones C (2013) Very high-resolution climate runs over Europe: an evaluation. The International Conference on Regional Climate - CORDEX, Brussels

Ludwig R, Roson R, Zografos C, Kallis G (2011) Towards an inter-disciplinary research agenda on climate change, water and security in Southern Europe and neighboring countries. Environ Sci Policy 14:794-803. doi:10.1016/j.envsci.2011.04.003

Meehl GA, Goddard L, Murphy J, Stouffer RJ, Boer G, Danabasoglu G, et al. (2009). Decadal prediction: can it be skilful? Bulletin of the American Meteorological Society, 90, 1467-1485, doi:10.1175/2009BAMS2778.1

Milano M, Ruelland D, Fernandez S et al (2013) Current state of Mediterranean water resources and future trends under climatic and anthropogenic changes. Hydrol Sci J 58:498-518. doi:10.1080/02626667.2013.774458

Murray SJ, Foster PN, Prentice IC (2012) Future global water resources with respect to climate change and water withdrawals as estimated by a dynamic global vegetation model. J Hydrol 448-449:14-29. doi:10.1016/j.jhydrol.2012.02.044

Navarra A, Tubiana L (2013) Regional assessment of climate change in the Mediterranean. doi: 10.1007/978-94-007-5772-1

Papagrigoriou S, Kaimaki S, Perleros S, Papageorgiou N, Lazaridis L (2001) Integrated Water Resources Management of Crete, 2001 (in Greek)

Raddatz TJ, Reick CH, Knorr W et al (2007) Will the tropical land biosphere dominate the climate-carbon cycle feedback during the twenty-first century? Clim Dyn 29:565-574. doi:10.1007/s00382-007-0247-8

Roeckner E, Brokopf R, Esch M et al (2006) Sensitivity of simulated climate to horizontal and vertical resolution in the ECHAM5 atmosphere model. J Clim 19:3771-3791. doi:10.1175/JCLI3824.1

Santos FD, Stigter TY, Faysse N, Lourenço TC (2013) Impacts and adaptation to climate change in the Mediterranean coastal areas: the CIRCLE-MED initiative. Reg Environ Chang 14:1-3. doi:10.1007/s10113-013-0551-2

Schewe J, Heinke J, Gerten D et al (2014) Multimodel assessment of water scarcity under climate change. Proc Natl Acad Sci U S A 111:3245-3250. doi:10.1073/pnas.1222460110

Scoccimarro E, Gualdi S, Bellucci A et al (2011) Effects of tropical cyclones on ocean heat transport in a high-resolution coupled general circulation model. J Clim 24:4368-4384. doi:10.1175/2011JCLI4104.1

Sherwood SC, Bony S, Dufresne J-L (2014) Spread in model climate sensitivity traced to atmospheric convective mixing. Nature 505:37-42. doi:10.1038/nature12829

Smith DM, Cusack S, Colman AW, Folland CK, Harris GR, Murphy JM (2007) Improved surface temperature prediction for the coming decade from a global climate model. Science 317:796-799. doi:10.1126/science.1139540
Sobolowski S, Petter L, Aristeidis K, Lennart M, Erik K, van Ulft B, Bastian E, Youmin C, Geert L, David Lindstedt IT (2014) Simulating extreme precipitation in the island of Crete with non-hydrostatic high-resolution RCMs, ECLISE collaborative FP7 research project under the Environment Programme of the European Commission, Deliverable 2.4

Storto A, Dobricic S, Masina S, Di Pietro P (2011) Assimilating along-track altimetric observations through local hydrostatic adjustment in a global ocean variational assimilation system. Mon Weather Rev 139:738-754. doi:10.1175/2010MWR3350.1

Swain RE, England Jr JF, Bullard KL, Raff DA, 2004. Hydrologic Hazard Curve Estimating Procedures. Dam Safety Research Report DS-04-08, Bureau of Reclamation, Denver, CO, $79 \mathrm{p}$

Taylor KE, Stouffer RJ, Meehl GA (2012) An overview of CMIP5 and the experiment design. Bull Am Meteorol Soc 93:485-498. doi:10.1175/BAMS-D-11-00094.1

Tsanis IK, Koutroulis AG, Daliakopoulos I, Michaelides S (2008) "Storm analysis and precipitation distribution of the flash flood in Almyrida basin, Crete", EGU2008 Session IS31-Flash floods: observations and analysis of atmospheric and hydrological controls, EGU, Vienna, Austria

Tsanis IK, Apostolaki MG (2008) Estimating groundwater withdrawal in poorly gauged agricultural basins. Water Resour Manag 23:1097-1123. doi:10.1007/s11269-008-9317-x

Tsanis IK, Koutroulis AG, Daliakopoulos IN, Jacob D (2011) Severe climate-induced water shortage and extremes in Crete. Clim Change 106:667-677. doi:10.1007/s10584-011-0048-2

Tsanis IK, Seiradakis KD, Daliakopoulos IN, Grillakis MG, Koutroulis AG (2014) Assessment of GeoEye-1 stereo-pair-generated DEM in flood mapping of an ungauged basin. J Hydrol 16:1

Van der Linden PMJ (ed) (2009) ENSEMBLES: Climate Change and its Impacts: Summary of research and results from the ENSEMBLES project. Met Office Hadley Centre, Exeter

Van der Plas EV, Wichers Schreur B, Kok K (2012) A quantitative evaluation of the high resolution HARMONIE model for critical weather phenomena. Adv Sci Res 8:149-155. doi:10.5194/asr-8-149-2012

Van Meijgaard E, van Ulft LH, van de Berg WJ, Bosveld FC, van den Hurk BJJM Lenderink GSA (2008) The KNMI regional atmospheric climate model RACMO, version 2.1 KNMI-publication TR-302. KNMI, De Bilt

Vaughan C, Dessai S (2014) Climate services for society: origins, institutional arrangements, and design elements for an evaluation framework. Wiley Interdiscip Rev Clim Chang 5:587-603. doi:10.1002/wcc.290

Voldoire A, Sanchez-Gomez E, Salas y Mélia D et al (2012) The CNRM-CM5.1 global climate model: description and basic evaluation. Clim Dyn 40:2091-2121. doi:10.1007/s00382-011-1259-y

Wang QJ (1997) Using genetic algorithms to optimise model parameters. Environ Model Softw 12:27-34. doi:10.1016/S1364-8152(96)00030-8

Weedon GP, Gomes S, Viterbo P, Osterle H, Adam JC, Bellouin N et al (2010) The WATCH forcing data 1958-2001: A meteorological forcing dataset for land surface and hydrological models. Watch Ed Watch Tech Rep 22:41

\section{Submit your manuscript to a SpringerOpen ${ }^{\circ}$ journal and benefit from:}

- Convenient online submission

- Rigorous peer review

- Immediate publication on acceptance

- Open access: articles freely available online

- High visibility within the field

- Retaining the copyright to your article

Submit your next manuscript at $>$ springeropen.com 